Missing Middle Housing in Toronto: Past \& Present Forms

By:

Ray Lister

BA (Hons), University of Victoria, 2014

A Major Research Paper

Presented to Ryerson University

In partial fulfillment of the requirements for the degree of

Master of Planning in

Urban Development

Toronto, Ontario, Canada, 2018 


\section{AUTHOR'S DECLARATION FOR DIGITAL SUBMISSION OF A MRP}

I hereby declare that I am the sole author of this MRP.

This is a true copy of the MRP, including any required final revisions.

I authorize Ryerson University to lend this MRP to other institutions or Individuals for the purpose of scholarly research.

I further authorize Ryerson University to reproduce this MRP by photocopying or by other means, in total or in part, at the request of other institutions or individuals for the purpose of scholarly research.

I understand that my MRP may be made digitally available to the public. 


\title{
Missing Middle Housing in Toronto: Past \& Present Forms
}

\author{
(C) Ray Lister, 2018 \\ Master of Planning \\ In \\ Urban Development \\ Ryerson University
}

\begin{abstract}
Toronto has a rich history of Missing Middle Housing forms that have contributed to the overall character of the city's built environment. The research paper maps the locations of Missing Middle Housing in Toronto, which I define as residentially zoned properties between 12 and 36 meters in height. It provides information on the broad development trends of this type of housing, and explores the forms of Missing Middle Housing in Toronto in the past and present. The research paper indicates that forms of Missing Middle Housing along avenues are being constrained by the City of Toronto's Mid-Rise Performance Standards (2010), making it challenging to build forms that have shaped Toronto's past.
\end{abstract}




\section{Acknowledgements}

I would like to extend my gratitude to a number of people that provided me with valuable assistance in the completion of this project.

Thank you to both my supervisor, Dr. Shelagh McCartney and second reader, Philippa Campsie, for the gift of their time and intellect. The advice and suggestions they provided have been key in shaping this project.

I would like to thank my classmates in the Urban Planning program for their support and inspiration over the last two years. It has been a pleasure learning alongside each of you.

Finally, my family and friends Monique, Charlotte and Alana, whose love and support helped me in the pursuit of this degree. 


\section{Table of Contents}

List of Figures................................................................................................................................................. vi

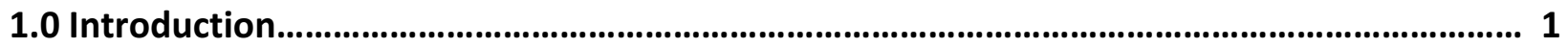

1.1 Defining Missing Middle Housing............................................................................... 2

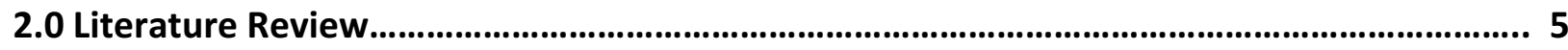

2.1 Benefits of Missing Middle Housing................................................................... 5

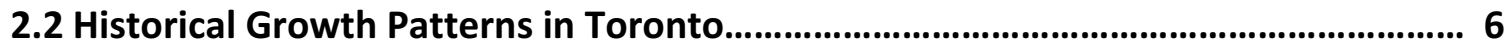

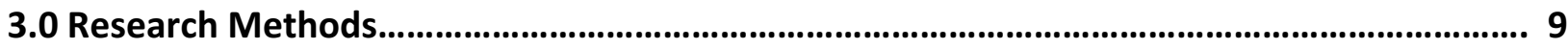

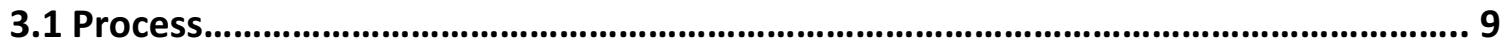

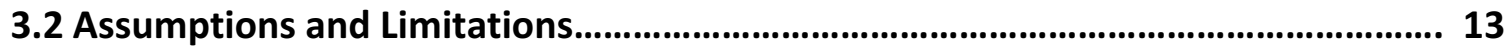

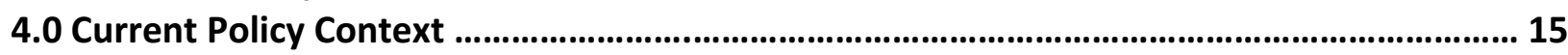

4.1 Growth Plan for the Greater Golden Horseshoe, 2006, 2017.................................. 15

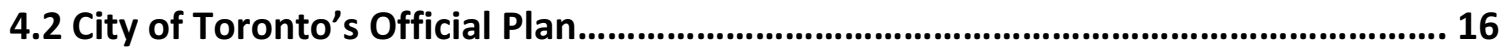

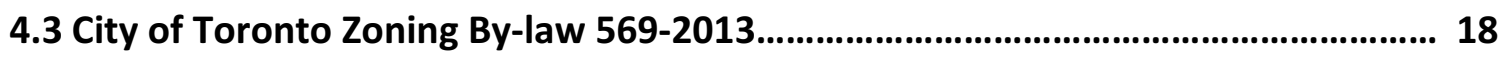

4.4 Mid-Rise Building Performance Standards.............................................................. 19

5.0 Development Patterns in Toronto......................................................................................... 21

5.1 Missing Middle Housing in Toronto............................................................... 22

6.0 Missing Middle Housing Typologies.................................................................................. 26

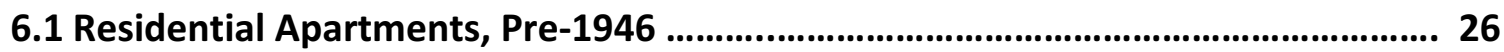

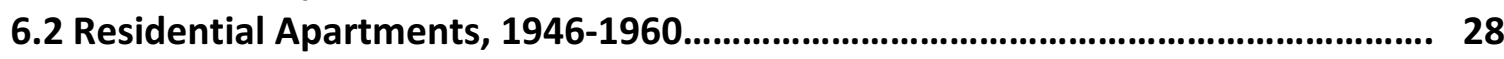

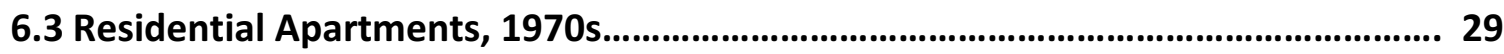

6.4 Commercial-Residential Apartments, 1980s......................................................... 31

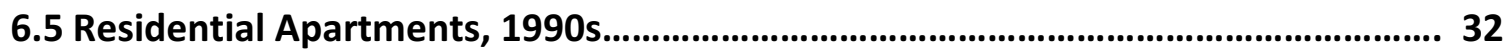

6.6 Commercial-Residential Apartments, 2000s........................................................ 33

6.7 Commercial-Residential Apartments, 2010s....................................................... 34

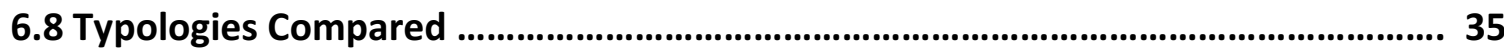

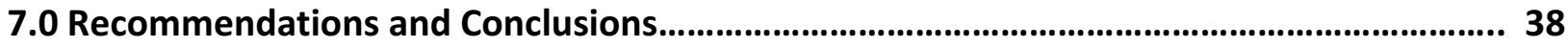

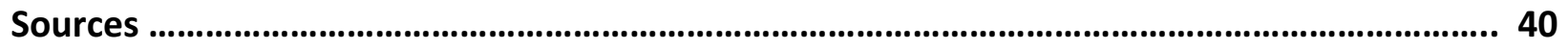

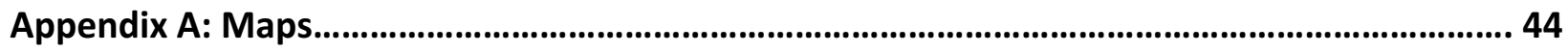




\section{List of Figures}

Figure 1: Missing Middle Housing Typologies..................................................................................... 3

Figure 2: Map of the Greater Toronto Area ....................................................................................... 7

Figure 3: Housing Units by Housing Type............................................................................................. 7

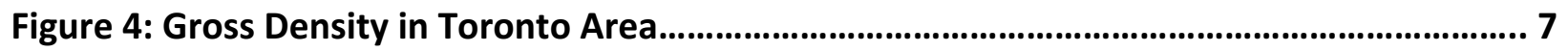

Figure 5: City of Toronto Year of Construction ......................................................................... 10

Figure 6: City of Toronto Residential Zoning Map ................................................................... 10

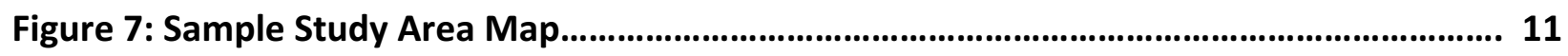

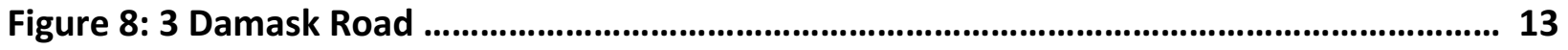

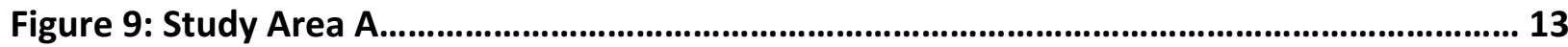

Figure 10: Growth Plan for the Greater Golden Horseshoe ................................................... 15

Figure 11: City of Toronto Official Plan, Urban Structures ........................................................... 16

Figure 12: City of Toronto Official Plan, Mid-Rise Building Design Guidelines.......................... 19

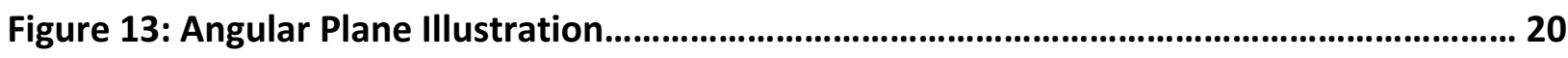

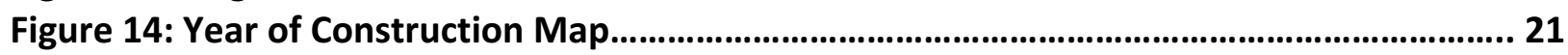

Figure 15: City of Toronto Residential Zones Map .............................................................. 22

Figure 16: Cost of Missing Middle Housing ................................................................................... 23

Figure 17: Map of Toronto's Missing Middle Housing ............................................................ 23

Figure 18: Average Height of Missing Middle Housing ..........................................................24

Figure 19: Share of Missing Middle Housing Properties by Zoning Category .......................... 24

Figure 20: Missing Middle Housing by Year of Construction................................................... 24

Figure 21: Average Height of Missing Middle Housing by Year............................................... 25

Figure 22: Residential Apartments, Pre-1946 ................................................................... 26

Figure 23: Courtyard Apartment with Mid-Rise Guideline Overlay............................................. 27

Figure 24: Residential Apartment, 1946-1960............................................................................. 28

Figure 25: Residential Apartment, 1970s............................................................................... 29

Figure 26: Residential Apartment, 1970s with Mid-Rise Guideline Overlay ............................ 30

Figure 27: Commercial-Residential Apartment 1980s........................................................... 31

Figure 28: Residential Apartment, 1990s...................................................................................... 32

Figure 29: Residential Apartment, 1990s with Mid-Rise Guideline Overlay............................ 33

Figure 30: Commercial-Residential Apartment, 2000s............................................................... 33

Figure 31: Commercial-Residential Apartment, 2010s............................................................... 34

Figure 32: Missing Middle Housing Typologies Compared ......................................................... 35 


\subsection{Introduction}

In Toronto, condominium towers are being built in great number, with 105,000 units currently under development in the year 2017 (Burda et al., 2017). This condominium tower development boom has been under way for over a decade, and it has allowed the City of Toronto to keep pace with growth targets mandated by the Province. Meanwhile, $31 \%$ of Toronto's land is zoned for single or semi-detached homes in the areas designated as stable neighbourhoods by our Official Plan (De Silva, 2017). The result is a city of extremes: a downtown core growing quickly with high-rise towers to accommodate an expanding population, and many low-rise neighbourhoods are stagnating or losing population (Weatherburn \& Davis, 2016), as the average price of MLS listed properties has risen by $\$ 300,000$ over the last five years (Toronto Real Estate Board, 2018). This development climate may contribute further to pressure on greenfield lands, encouraging urban sprawl to respond to market demands for more affordable and right-sized family-friendly housing (Burda et al., 2017). This polarization also endangers Toronto's long-held reputation as a city of neighbourhoods.

These extremes of high rise development of 12 or more storeys and low-rise residential neighbourhoods, often 1-3 storeys, has resulted in a condition where the forms of development between 4 and 11 storeys do not occur at nearly the same pace. Buildings within this height are typically built more densely and create very lively urban conditions globally. These missing building of this middle height of 3-11 storeys that occupy many celebrated urban realms globally is referred to as Missing Middle Housing. In Toronto, one possible response to the polarization of building types is the increased construction of Missing Middle Housing. These forms have not been built in great number since the 1940s. The absence of Missing Middle Housing in Toronto has been noted in the media (Kalinowski, 2016; Tuckey, 2017). The broad conversation surrounding the Missing Middle in Toronto assumes that such housing must be built in the form of duplexes, stacked townhouses and mid-rise buildings (Burda et al., 2016). Cherise Burda (2015) has argued that more permissive conditions, such as rezoning and lower 
minimum parking requirements, will not only allow, but encourage, the development of Missing Middle Housing at a faster pace for a less expensive sale price. Major research papers from the School of Urban and Regional Planning at Ryerson University have further discussed the challenges developers face in building mid-rise housing, particularly the lack of certainty brought on by under-zoning on Toronto's avenues (Beaumont, 2012; Brown, 2012; Sotomayor, 2016). This means that Toronto's avenues are typically zoned for heights below four storeys, which dis-incentivizes development by necessitating a time-consuming application for re-zoning if a developer wishes to build many forms of Missing Middle Housing.

This major research paper, Missing Middle Housing in Toronto: Past \& Present Forms, will examine existing forms of Missing Middle Housing in Toronto. I will advance the argument that Toronto has a rich history of diverse housing forms that are being constrained by more recent regulations, while leading urbanists in Toronto express desire to follow the lead of Vancouver in taking measures to improve housing affordability, which includes the construction of more Missing Middle Housing (Keesmaat, 2017). Missing Middle buildings are found under different residential zoning categories across the city, were built in different eras and exhibit different characteristics that contribute to the character of Toronto's neighbourhoods and avenues. I argue that Toronto is home to many different types of Missing Middle Housing that could not be built today due to zoning regulations and design guidelines such as the in-force Performance Standards for Mid-Rise Buildings (2010) released by the City of Toronto. These regulations and design guidelines, then, could be made more flexible to allow for alternate forms of Missing Middle Housing that contribute to a sense of place in Toronto and add diversity to a housing market that has become increasingly polarized.

\subsection{Defining Missing Middle Housing}

Missing Middle Housing is a term popularized by California-based architect and planner Dan Parolek (Kolson Hurley, 2016). His idea of Missing Middle Housing occupies the conceptual space between single-detached dwellings and mid-rise buildings, and includes duplexes, courtyard apartments and live-work units (Figure 1). Parolek defines the Missing Middle as 
housing that contributes to a walkable neighbourhood context within an urban setting, characterized by densities ranging from 16 to 35 dwelling units/acre achieved with small building footprints, smaller unit sizes, community-oriented design, simple construction and minimal off-street parking (Parolek, 2015). Missing Middle Housing is so named because "very few of these housing types have been built since the early 1940s due to regulatory constraints, the shift to auto-dependent patterns of development, and the incentivization of single-family home ownership" in North America (Parolek, 2015, 2).

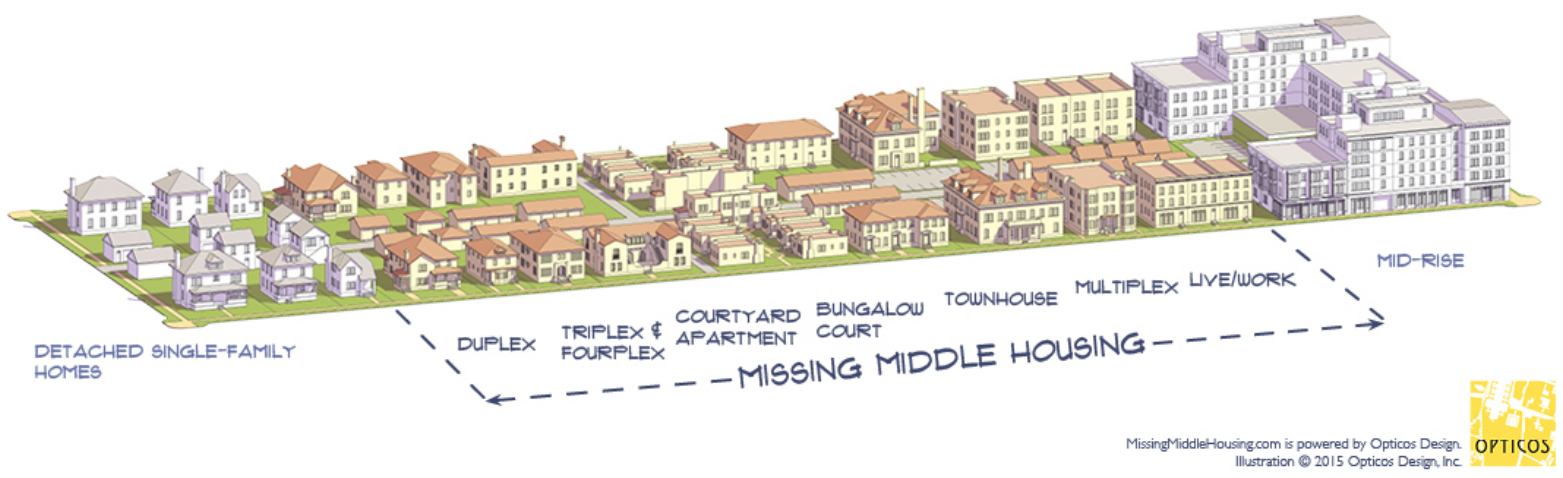

Figure 1: Missing Middle Housing Typologies, as presented by Dan Parolek of Opticos Design. My definition of Missing Middle Housing in Toronto is scaled up between 4 and 11 storeys and includes mid-rise buildings to reflect Toronto's relatively dense built form. (Source: Opticos Design, 2015)

Parolek's definition of Missing Middle Housing has been expanded by other city builders. Intrator \& Shivdikar (2017) have expanded the term to refer to housing quality as well as housing typology. Within the housing policy realm, the term is now also being applied to moderate-income households for which few subsidies exist (Paulsen, 2017).

While Parolek's definition of Missing Middle Housing is a good starting point, it was developed in a different urban context from that in Toronto, where the metropolitan region supports an average of 27 people per hectare across the entire built-up region, the same density as Stockholm or Copenhagen (Sorensen \& Hess, 2014). In my view, the Missing Middle is defined by its form, function and relative scarcity. In the Toronto context, I define the Missing Middle as properties between 12 and 36 metres in height (4-11 storeys) within residential or commercialresidential zones. This definition captures forms between high-rise towers and standard 2-3 storey single and semi-detached homes. There are limitations to this definition that I will 
R. Lister - Missing Middle Housing in Toronto: Past \& Present Forms - 2018

discuss in Section 3.0, Research Methods. However, as my research will show, these buildings are most often located in transit-supportive neighbourhoods or dense commercial corridors around the city centre, and the majority were constructed before 1946 . The forms of Missing Middle Housing I have identified are dense in comparison with those Parolek has illustrated above (Figure 1) and these forms contribute to Toronto's history of relatively dense urban form. The re-introduction of similar forms at similar densities will contribute to Toronto's future as an increasingly dense city while still respecting the scale of Toronto's nearby designated stable neighbourhoods. 


\subsection{Literature Review}

A study of the benefits of Missing Middle Housing and growth patterns in Toronto was conducted to inform the research paper. During this review, I have found that Missing Middle Housing is seen as a cost-efficient means of adding more density in Toronto's neighbourhoods (Burda et al., 2017), that it can benefit from energy-efficient construction techniques (Gibson, 2014), and that it can support urban consolidation efforts through gentle intensification (Buxton \& Tieman, 2005).

\subsection{Benefits of Missing Middle Housing}

Missing Middle Housing can help to close the gap between high-rise investment units and expensive single- or semi-detached homes for home buyers. In a 2012 Royal Bank of Canada (RBC) study, it was found that over $80 \%$ of Greater Toronto Area residents would choose to live in a 'location efficient' neighbourhood, in other words, one that is transit-supportive, walkable and provides shorter commute times, and would give up the aspiration of owning a large home and yard in a less efficient location (Burda, 2013). Missing Middle Housing can provide units that support these goals. Additionally, Ryerson $\mathrm{CBI}$ has found that the sale price of units in Missing Middle typologies are typically more affordable than single- or semi-detached residential units (Burda et al., 2016). More recently, it has been argued that constructing more Missing Middle Housing is a crucial way to increase the density of neighbourhoods by constructing more family-friendly units in the City of Toronto (Burda et al., 2017).

Missing Middle Housing can also be environmentally conscious built forms. The use of renewable materials in the construction of Missing Middle Housing can ensure these forms are an environmentally friendlier approach to building when compared to towers (Sotomayor, 2016). Furthermore, it has been shown that mid-rise buildings can operate at twice the energyefficiency per square metre when compared with high-rise towers (Gibson, 2014). Wood frame construction of up to six storeys can now be used in the building of Missing Middle Housing in 
Toronto. This move to increasing the height allowance for wood frame, which is a renewable material, can have profound benefits by substantially reducing the production of onsite waste during the construction period (Gibson, 2014). This is particularly desirable in the case of infill construction projects along avenues and residential streets, as it will reduce disruption due to construction waste and help to speed the process.

Missing Middle Housing can contribute to urban consolidation efforts, which are broadly considered to be economically, socially and environmentally good planning practice (Buxton \& Tieman, 2005). Intensification-oriented regional policies will be explored in later sections of this research paper in greater detail. In the Toronto context, urban intensification is a key policy objective of both the provincial and municipal governments. It is argued that "if we want to build a more affordable region, while protecting our valuable natural capital and agricultural lands [...] we must do a better job at planning for intensification" (Haines \& Aird, 2018). Missing Middle Housing is one means of accomplishing intensification within the built-up area. Mid-rise Missing Middle forms provide density needed to support rapid transit while having the ability to fit into the character of a neighbourhood better than high-rise buildings (Sotomayor, 2016). Thus, Missing Middle Housing can respond to local market preferences for 'location efficient' neighbourhoods (Burda, 2013).

\subsection{Historical Growth Patterns in Toronto}

Increasing density is a popular argument for developing more Missing Middle Housing, and I am also advancing that argument within this research paper. Literature on the planning and growth of Toronto generally focuses on the regional scale (Filion, 2000; Solomon, 2007; Sewell, 2009), perhaps because the Toronto area is known for innovative regional-scale planning (Sorensen \& Hess, 2014). Within this body of literature, however, there is disagreement about whether or not the Greater Toronto Area's historical growth patterns amount to urban sprawl. Missing Middle Housing is a means of intensification, and understanding the historical growth patterns of the Toronto area is an important first step in constructing a place-based concept of the Missing Middle. 


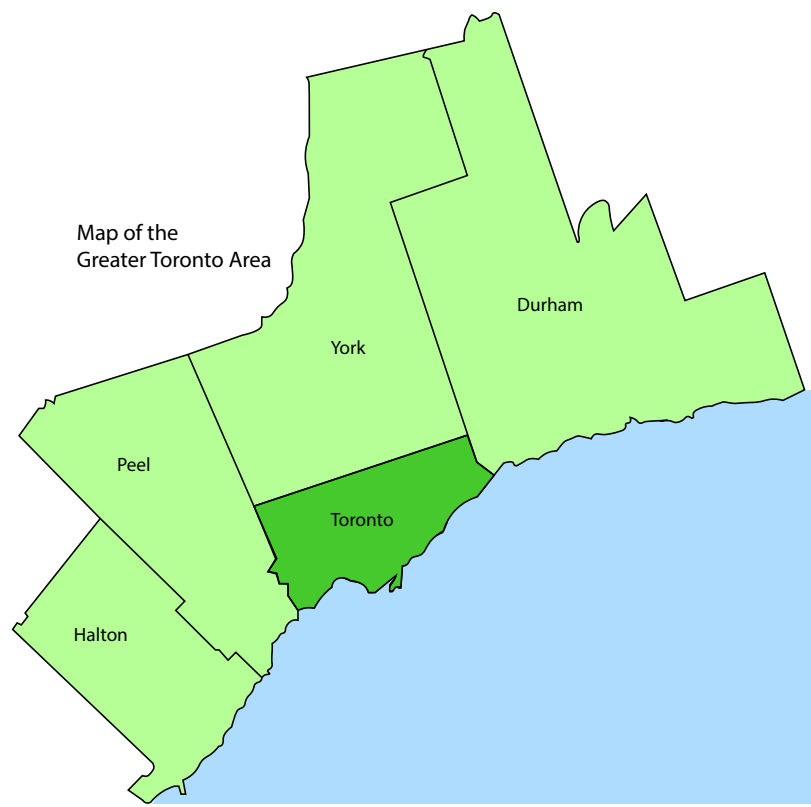

Figure 2: Map of the Greater Toronto Area. R. Lister, 2018.
Academics such as Solomon (2007) and Sewell (2009) have argued that the Greater Toronto Area (see Figure 2) has, much like other North American cities, developed autodependent post-war suburbs that exhibit the characteristics of urban sprawl. This view has prompted discussion around solutions such as transit-oriented design, which includes Missing Middle Housing typologies (Rai, 2007). Solomon (2007) has argued that automobile dependency is more a symptom than a cause of sprawl, and that Toronto's regional sprawl was caused by governments' interest in dispersing the public, enacted by policy measures and incentivized by inexpensive land costs. Blais (2010), has argued that planning for density in this region has been stymied by incorrect pricing of municipal services contributes to subsidizing sprawling development.

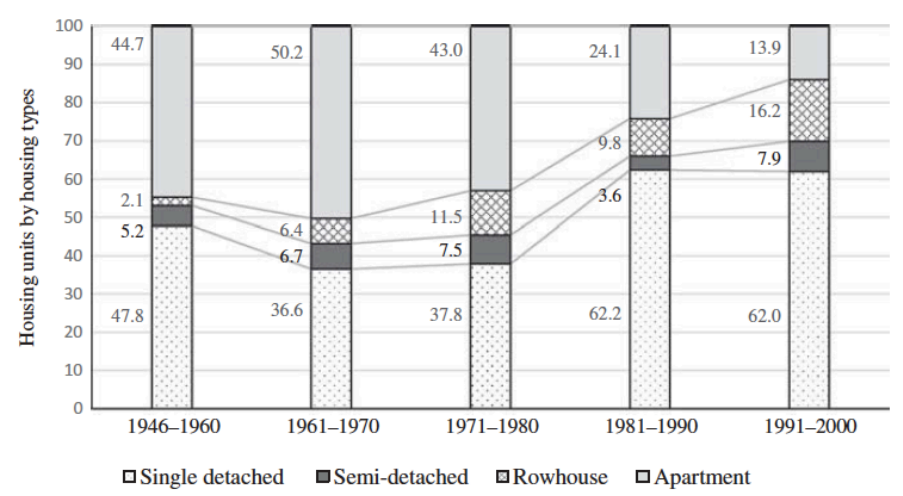

Scholarship by Hess \& Sorensen $(2014 ; 2015)$ and Moore (2000) takes a different view of Toronto's development history. Hess \& Figure 3: Housing units by housing type in Toronto area. (Source: Hess \& Sorensen, 2015).

Sorensen (2014) suggest that the Toronto region is unique among mid-sized metropolitan regions in North America in creating relatively dense suburbs with a mix of housing types and continuity of built form

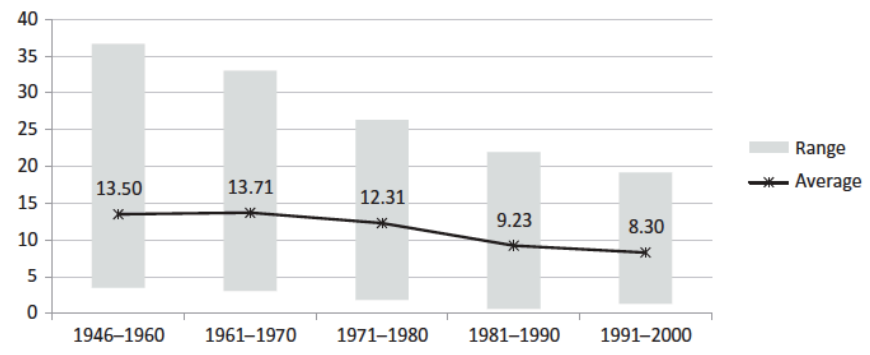

Figure 4: Gross density in Toronto area (units per hectare). (Source: Hess \& Sorensen, 2015). 
over decades. They argue that Toronto's development in the last 50 years does not amount to urban sprawl upon analysis of the urban form, gross and net housing density, and housing mix since 1946 (Hess \& Sorensen, 2015). They show that Toronto's residential density has fallen in recent years due to an increase of mixed-use development and greater investment in greenspace (Figures 3 and 4). Moore (2000) contests that Toronto did not suffer urban decentralization in the same way many North American cities did throughout the 1960s and 1970s. Instead, Toronto saw its last rental apartment boom at that time. These rental apartments are captured in my Missing Middle Housing typology research.

My research supports the arguments advanced by Moore (2000) and Hess \& Sorensen (2014; 2015) in that I have found that Toronto does have a rich history of Missing Middle Housing development that contributes to the relatively dense urban fabric of Toronto. However, my research does indicate that Missing Middle Housing between 4 and 11 storeys is unevenly clustered in the Old City of Toronto and more or less absent from Toronto's more suburban areas, except in select Residential Apartment areas. This means that Toronto has a legacy of Missing Middle Housing in the urban core and pre-war suburban contexts that could serve as precedents for the more recently built reaches of the City. My research also shows that Missing Middle Housing in Toronto has not been built in great number since before 1946 . We are also seeing a relative increase in Missing Middle Housing under 12 storeys in the Greater Toronto Area, outside of the City of Toronto boundary, as these municipalities respond to Growth Plan density targets (Burda et al., 2017). 


\subsection{Research Methods}

This section describes the research process undertaken to produce this major research paper. It also discusses the assumptions and limitations in producing this research.

\subsection{Process}

This research was undertaken in five parts. First, a current policy context review was done to ensure a comprehensive understanding of how Missing Middle Housing is regulated and constrained at present. At the provincial level, the Growth Plan for the Greater Golden Horseshoe was examined because it sets out density targets and population forecasts that municipalities must plan to accommodate. The Plan provides policy impetus for municipalities to consider tools such as Missing Middle Housing to promote density in urban centres and transit corridors. Further examination of Toronto's municipal policies and guidelines was undertaken in order to understand policy moves to accommodate more Missing Middle Housing in Toronto, as well as the ways in which these policies constrain and regulate development of such housing forms.

Second, a literature review of scholarly articles on Toronto's growth and policy history was completed to gain knowledge of the ways that policy has regulated development over time. The results of that enquiry are found above in Section 2.0, Literature Review. That work helped to further my understanding of Toronto as a city with a unique history of regional planning, and provides confirmation that Toronto has a history of Missing Middle Housing development that has been decreasing over time. 


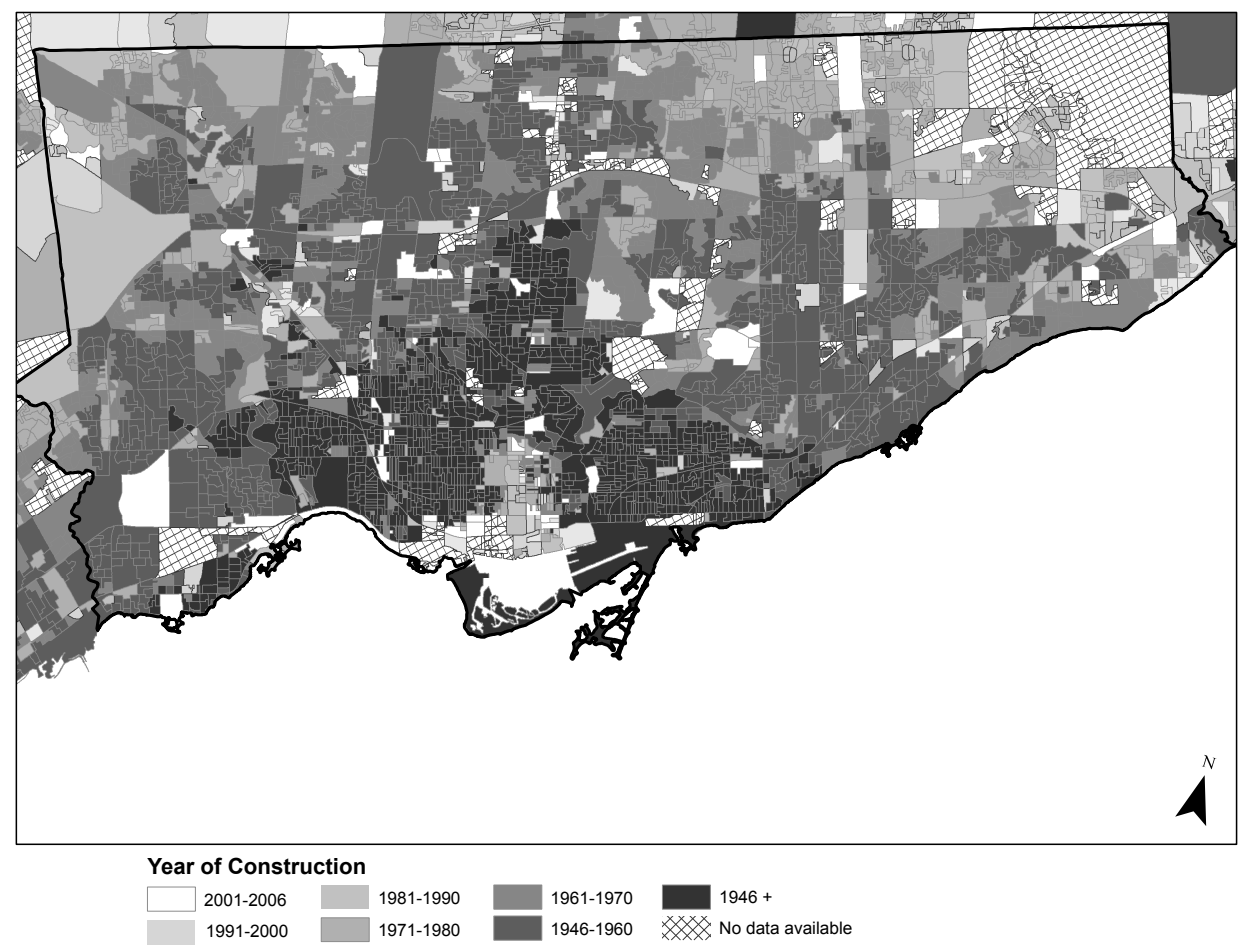

Figure 5: City of Toronto Map showing period of construction data. R. Lister, 2018.

Third, I undertook a mapping project to visualize the distribution of Missing Middle Housing throughout the city. To accomplish this, I used 2006 census data to find the period of

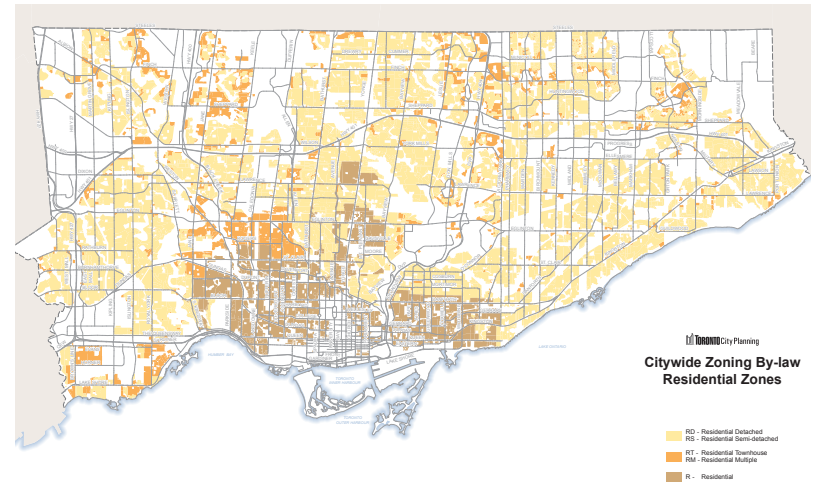

Figure 6: City of Toronto Residential Zoning Map construction most prevalent in Dissemination

Areas (DAs) within the boundaries of the City of

Toronto (Figure 5). I used the 2006 census data because in 2011, Statistics Canada shifted from a mandatory long form survey to a voluntary National Household Survey. This choice was the subject of significant criticism from the National Statistics Council (McDaniel \&

MacDonald, 2012), and further, this choice "has the potential to further undermine survey quality and coverage" (Kukutai et al., 2014, 18). More specifically, my study maps Missing Middle Housing by period of construction and the data for dwellings built between 1981-1985 were considered to be over-reported in the 2011 National Household Survey (Statistics Canada, 2011). This means that using 2011 National Household Survey data would have showed an inflated amount of Missing Middle Housing construction from 1981-1990 in my research. The 
2016 census data for period of construction was released on March 28, 2018 (Statistics Canada, 2018), while the research for this major research paper was completed in October of 2017. For these reasons, I chose to utilize 2006 census data. I performed a spatial join of the census period of construction data to 3D massing data from the City of Toronto. Then, I excluded all joined data on buildings that were not between 12 and 36 meters in height and within residential zoning categories, as per the City of Toronto zoning layer (Figure 6). The resulting maps are found in Section 5.0 as well as Appendix A. This mapping informed the research in two ways: it allowed for the production and analysis of data to discover broad trends in Missing Middle Housing within Toronto, and provided the basis for selecting study areas.

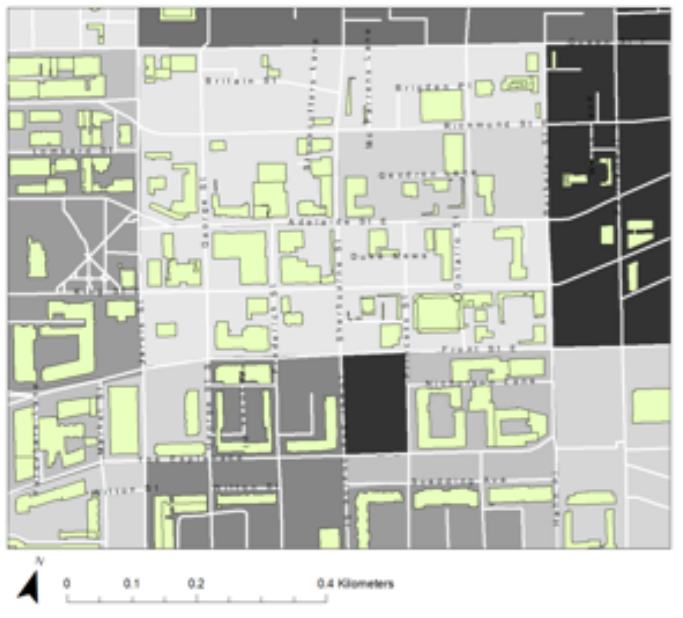

Figure 7: Sample Study Area map, R. Lister, 2018.
The fourth step of research was selecting and examining study areas to begin refining Missing Middle Housing typologies. Using the maps produced in step three, I visually identified study areas showing clusters of Missing Middle Housing starting in Toronto's historic core and radiating out to more recently developed DAs. I identified eight study areas with clusters of Missing Middle Housing developed in different decades of construction (an example can be found in Figure 7), which are explored in greater detail in Section 5.0.

Finally, I examined the Missing Middle Housing present in each study area to develop the typologies in Section 6.0 of this report. I informed my typologies with selected properties which were consistent with architectural styles from the periods of construction through site visits where possible and Google streetviews where necessary. These typologies are composites that represent some of the forms of Missing Middle Housing within different decades of development in Toronto. They contribute to a richer understanding of what Missing Middle 
R. Lister - Missing Middle Housing in Toronto: Past \& Present Forms - 2018

Housing looks like in Toronto and what might be possible once again if regulations were adjusted accordingly. 


\subsection{Assumptions and Limitations}

Mapping the Missing Middle on a City-wide scale requires the use of assumptions. As mentioned above, I defined my search for Toronto's Missing Middle Housing as properties

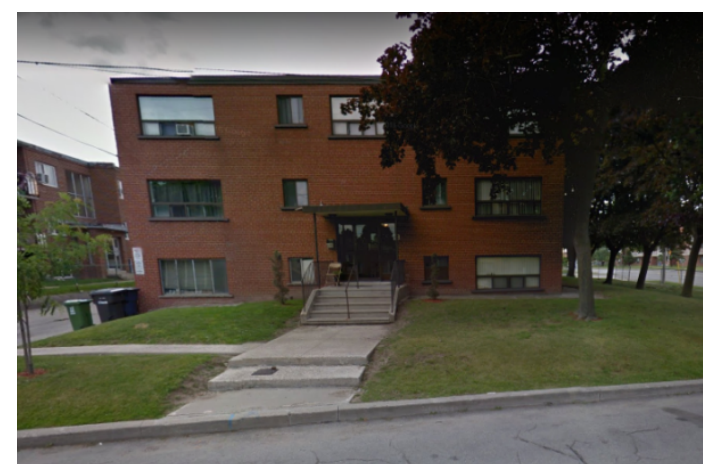

Figure 8: 3 Damask Road, Toronto is not captured within this data, despite it being a recognized Missing Middle Housing typology. Source: Google Street View, 2017. between 12 and 36 metres in height (4-11 storeys)

within residential or commercial-residential zones.

These zoning categories were chosen to avoid capturing non-residential buildings, such as industrial buildings, in this dataset. This definition is meant to capture intermediate forms between high-rise towers and standard 2-3 storey single and semi-detached houses. This work produced 11,194 data points and helped me broaden my examination of Missing Middle forms beyond those I noticed in my own travel through the City of Toronto. These data inform Section 5.0, and the typologies developed in Section 6.0.

There are limitations to these research methods. Building height is an imperfect predictor of density (Campoli \& McLean, 2002). Setting the building heights between 12 and 36 meters was done to avoid capturing the many 2-3 storey single-family homes of Toronto's stable

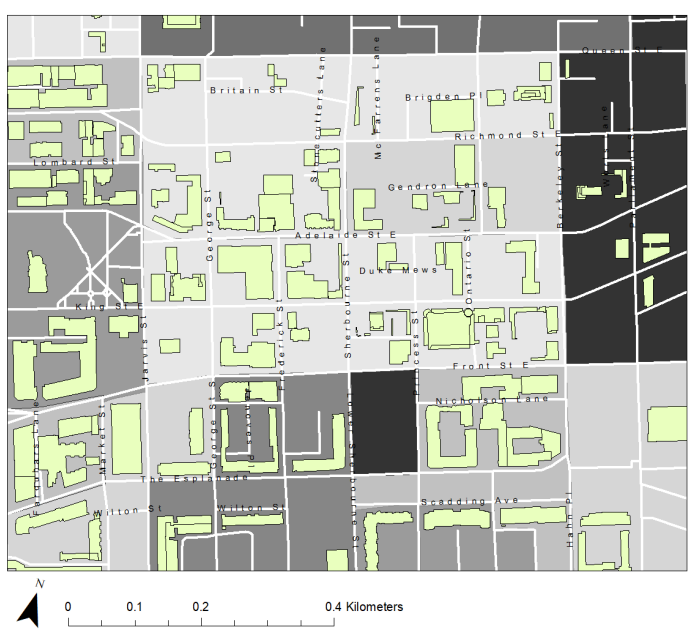

Figure 9: Study Area A. See appendix for larger view. $R$. Lister, 2018. neighbourhoods, though this choice means that many 3-storey apartment buildings (see Figure 8) were likely excluded from the data, although they meet many of the functional goals that mid-range housing looks to achieve.

While the data include only properties within residential zoning codes, they include Commercial Residential and Commercial Residential 
R. Lister - Missing Middle Housing in Toronto: Past \& Present Forms - 2018

Employment zones. This was done to capture buildings along avenues and in redeveloped areas within the downtown core that likely contain residential units. However, this means that the data include some buildings that are being used primarily as offices instead of residential buildings. Additionally, these areas have many towers that are taller than 36 meters, with podiums that were captured within the data as they are between 12 and 36 meters. Those buildings were identified through visual inspection (see Figure 9) and were not considered during the development of typologies for Section 6.0, but they remain within the data that inform Section 5.0. These imperfections have not been removed due to time constraints and the volume of data. 


\subsection{Current Policy Context}

A variety of policies govern the current development landscape in Toronto. The following are key policies that relate to Missing Middle Housing.

\subsection{Growth Plan for the Greater Golden Horseshoe, 2006, 2017}

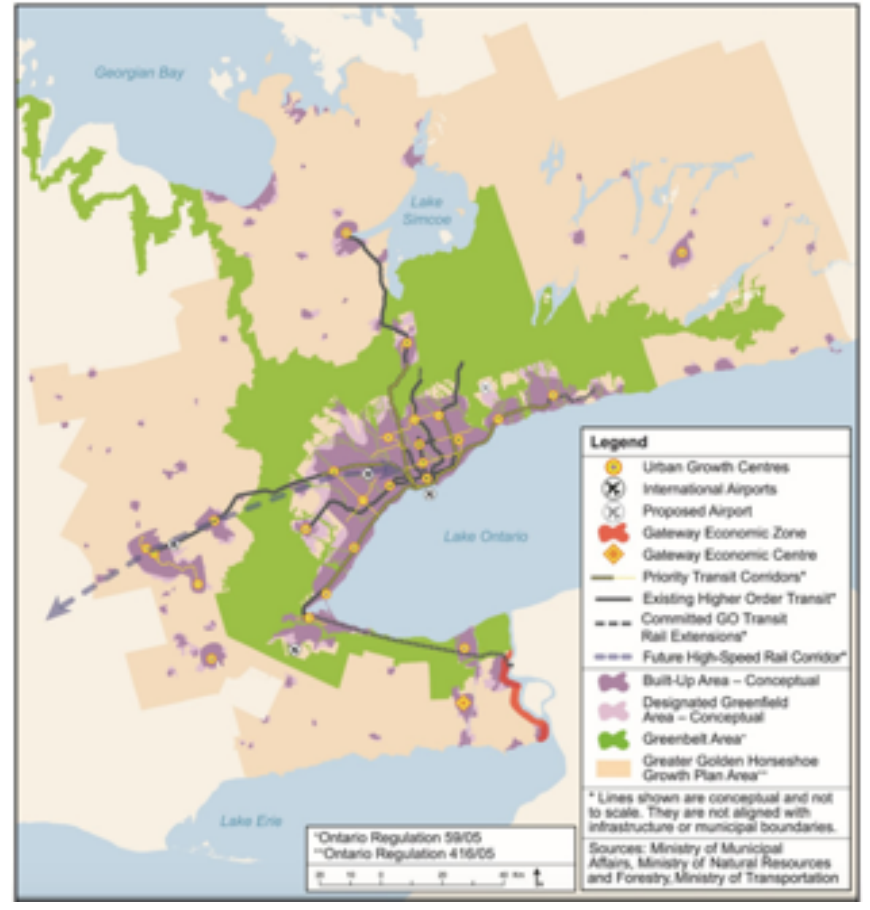

Figure 10: Growth Plan for the Greater Golden Horseshoe.
Prior to The Growth Plan for the Greater Golden Horseshoe (Growth Plan) of 2006, the Province of Ontario released the Places to Grow Act (2005) which lays out the policy framework for the Growth Plan. Within this policy framework, building "complete communities" and "making efficient use of infrastructure" (Province of Ontario, 2005, Preamble) is highlighted as a priority. These directives are reflected in the City of Toronto's Official Plan (see Section 4.2 below). The Growth Plan also directs municipalities to:

develop a strategy to achieve the minimum intensification target [...] which will:

a. encourage intensification generally to achieve the desired urban structure;

b. identify the appropriate type and scale of development and transition of built form to adjacent areas;

c. identify strategic growth areas to support achievement of the intensification target and recognize them as a key focus for development;

d. ensure lands are zoned and development is designed in a manner that supports the achievement of complete communities; 
e. prioritize planning and investment in infrastructure and public service facilities that will support intensification; and

f. $\quad$ be implemented through official plan policies and designations, updated zoning and other supporting documents (Policy 2.2.2(4), emphasis added).

These directives, along with a projected population of 3,190,000 for the City of Toronto by 2031 (Growth Plan, Schedule 3) indicate a pressing need to accommodate population growth through residential intensification, and to zone appropriately.

The Growth Plan (amended 2017) sets growth targets for urban areas while working in harmony with environmental policies such as the Greenbelt policy. Together, these policies protect the natural resources of the Greenbelt area (Figure 10) from development, effectively curbing urban sprawl. The Growth Plan mandates smart growth intensification in urban centres and transit corridors. This provides the policy impetus for municipalities in the Greater Golden Horseshoe area to consider ways of intensifying the built form environment while maintaining an appropriate scale of development for the community and to update their Official Plans accordingly. Throughout the region, municipal policies have been designed to accommodate mid-rise intensification, specifically along urban corridors or avenues (Bedford, 2013). In response to these growth targets, municipalities are now seeing an increased proportion of condo housing units in mid-rise Missing Middle buildings (Burda et al., 2017).

\subsection{City of Toronto's Official Plan}

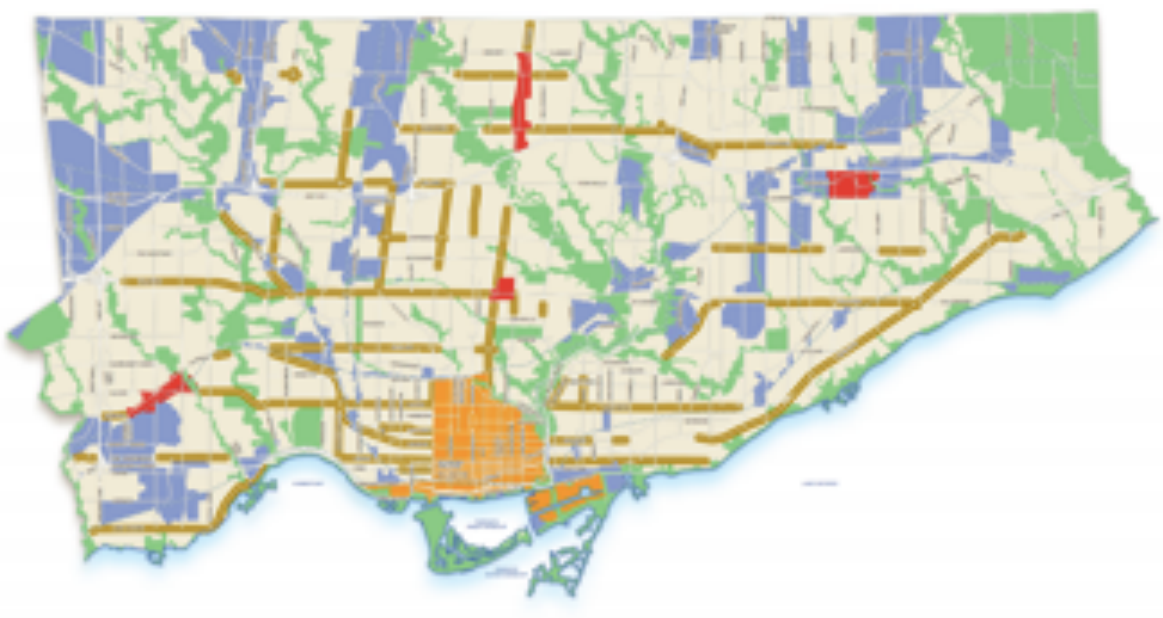

The City of Toronto's

Official Plan sets out the vision for growth of Toronto. Chapter two of the Official Plan states that "when planning for 
housing in Toronto [...] we have to offer a broader choice of housing type, tenure and affordability, both within Toronto and beyond" (City of Toronto, 2015, 2).

Map 2 of the Official Plan (Figure 11) indicates the high-level urban structure of Toronto. The light tan areas are residential neighbourhoods that are not expected to accommodate much population growth. These areas have restrictive zoning that makes medium-density developments difficult to achieve. Growth is to be concentrated on Avenues (gold), the Downtown Core (orange) and growth centres (red). Of interest to this report, the Avenues are expected to "emphasize residential growth" (City of Toronto, 2015). This emphasis on residential development along Avenues is a continuation of an earlier Main Streets Initiative (Gibson, 2014).

The City of Toronto's Official Plan Section 2.2.3 outlines a vision of accommodating growth through increasing density along Avenues, and while areas designated as Avenues within the Plan are considered important corridors for reurbanization and the growth of new housing and job opportunities, the Plan is explicit that "where a portion of an Avenue is designated as a neighbourhood, the neighbourhood protection policies of Chapter 4.1 will prevail to ensure that any new development respects and reinforces the general physical character of established neighbourhoods." (City of Toronto, 2015, 2-16) Further, the Official Plan insists that reurbanization of the Avenues will be achieved via Avenue Studies (Policy 2.2.3(1)).

From a city-building perspective, the incremental Avenue Study approach means that developments along Toronto's Avenues may have the chance to enhance the feeling of community involvement in decision making and design. From an economic perspective, this means that the rezoning of Toronto's Avenues will be a lengthy, expensive and piecemeal process. Some have argued that this approach to re-zoning the Avenues contributes to a sense of developer uncertainty and a general lack uptake due to financial infeasibility in Toronto (Brown, 2012). This outcome is unfortunate, given the evidence linking zoning changes to increased housing costs as well as geospatial inequity (Fyall et al., 2017). It has been suggested 
that the City of Toronto is purposefully under-zoned in order to receive Section 37 contributions from developers (Moore, 2000). This means that the City of Toronto may receive community benefits, such as new facilities or cash payments, for developments that are built beyond what the zoning of the site allows. This practice is commonly known as density bonusing.

\subsection{City of Toronto Zoning By-law 569-2013}

The City of Toronto Zoning By-law was enacted in 2013 and is in effect, though portions of it remain under appeal. The Zoning By-law regulates the use of land including the lot coverage, height, location, erection and use of buildings and structures within the City of Toronto. It also provides regulations on parking provisions and loading spaces. Within the Zoning By-law, land use categories of interest to this study are Residential, Residential Apartment, Commercial Residential and Commercial Residential Employment.

Toronto's Zoning By-law is acknowledged to be a key constraint on mid-rise development by Pembina Institute. In their report, Make Way for Midrise, Burda \& Collins-Williams (2015), it is recommended that the City of Toronto re-zone existing areas along rapid transit lines for higher densities. They suggest that zoning along Avenues burdens developers of mid-rise buildings with a long and uncertain approval process and state that this process makes it "costprohibitive to build mid-rise developments" (Burda \& Collins-Williams, 2015, 9). This means that developers may have to apply for re-zoning to build a mid-rise building along an avenue. Reducing the length of the planning approval process was also noted by the Canadian Urban Institute (2009) to be a top priority to encourage more mid-rise development (Sotomayor, 2016). The City's parking ratio, enforced through the Zoning By-law, is also noted to be a barrier to mid-rise Missing Middle Housing development along Toronto's Avenues (Brown, 2012). Parking, especially underground parking, adds additional cost to development along transit corridors where parking may not be necessary for many residents. 


\subsection{Performance Standards for Mid-Rise Buildings}

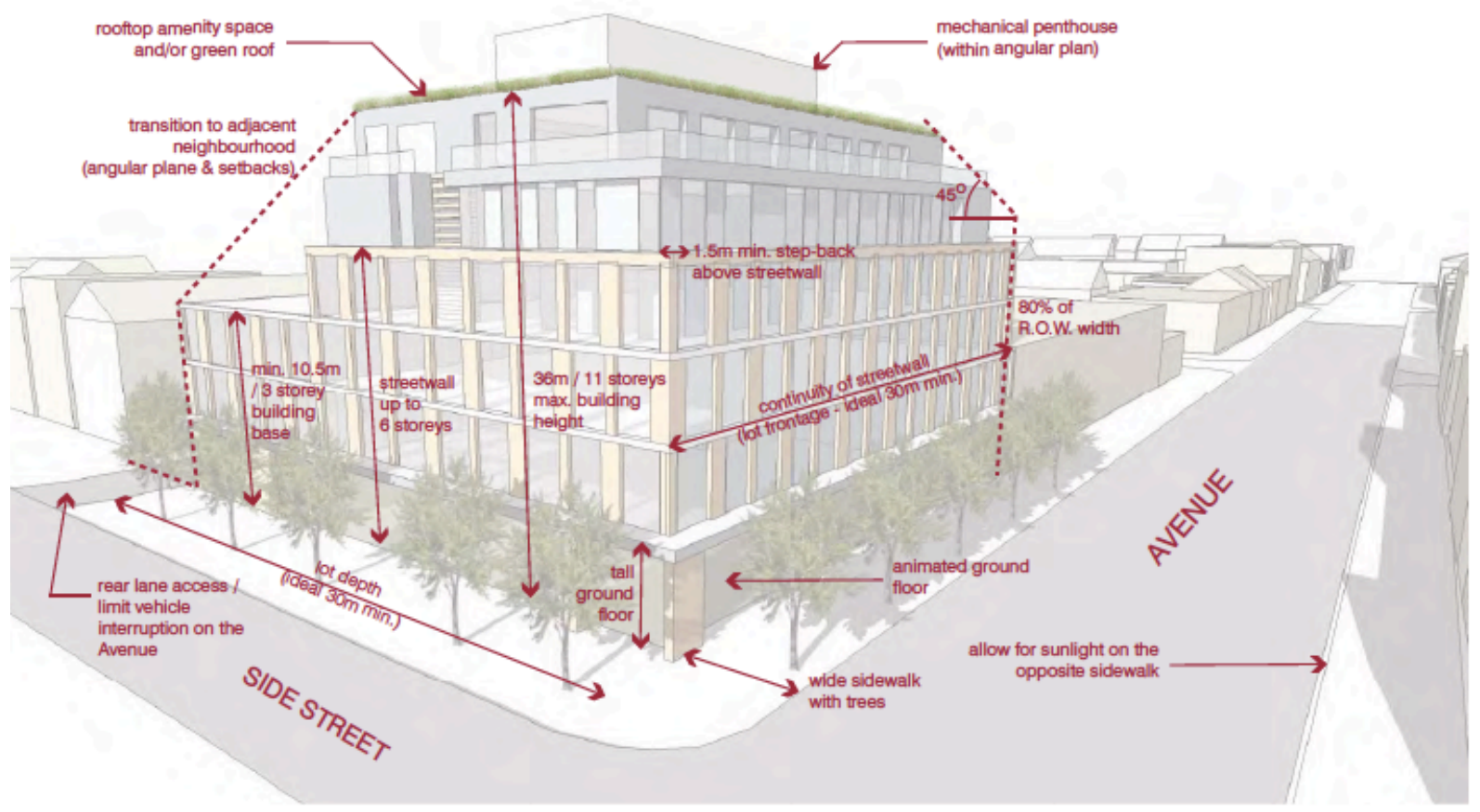

Figure 12: City of Toronto Official Plan, Performance Standards for Mid-Rise Buildings, 2010.

The City of Toronto adopted their Performance Standards for Mid-Rise Buildings in 2010, and adopted an addendum to the Standards in 2016. These standards set out best practices for midrise building massing as well as height in relation to street width along Avenues. The Performance Standards are meant to encourage mid-rise forms that preserve view corridors along Avenues and maintain transitions to low-rise neighbourhood built forms while also encouraging greater residential density.

Figure 12 illustrates the performance standards for mid-rise buildings. The maximum allowable height of buildings on avenues is no taller than the width of the right-of-way of the avenue, up to a maximum height of 36 metres (11 storeys). This means that if a street has a 20 metre rightof-way, a mixed-use building could be 20 metres tall, or 6 storeys (City of Toronto, 2010, 36). The guidelines further limit commercial use buildings to 5 storeys along a 20 metre right-ofway. This is an interesting way to encourage mixed-use buildings, and it is a practice that has been in use in Toronto since the Central Area Plan of 1976 (White, 2016). Another striking 
feature of the mid-rise performance standard is the step back requirement. At eighty percent of the height of the building, the avenue-facing frontage must stepback by a minimum of 1.5 meters, creating a 45-degree plane. On the rear side of the building, a 10.5-meter wall must step back at a 45-degree angular plane (Figure 13). This is prescribed to protect nearby residential buildings from crowding or privacy concerns.

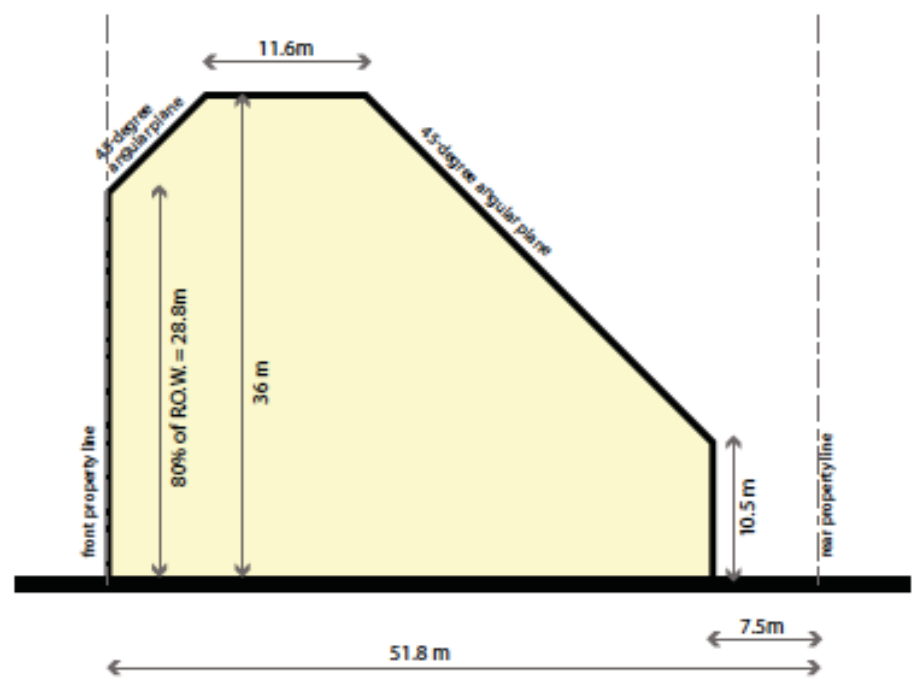

Figure 13: Angular Plane illustration, City of Toronto Mid-Rise Guidelines, 2010.

Brown (2012) has highlighted criticism of these guidelines by development industry insiders, who suggest that they further strain the financial feasibility of mid-rise buildings in Toronto while not considering the specific needs of each lot. While the guidelines do not have official status, they are "prescriptive across a variety of sites, [and] create issues for application[s]" including application delays and additional cost (Brown, 2012, 33). These guidelines constrain the design of future mid-rise Missing Middle typologies and ignore different forms of mid-rise buildings that already exist within the Toronto context and manage to accomplish the goals of these guidelines. 


\subsection{Development Patterns in Toronto}

In order to understand past Missing Middle Housing forms in Toronto, we must first understand how the city has grown over the years. Census data is one way of determining the broad trends of development and redevelopment in Toronto. Figure 14 uses dwelling period of construction data from the 2006 census. It displays the most common year of construction within each Dissemination Area.

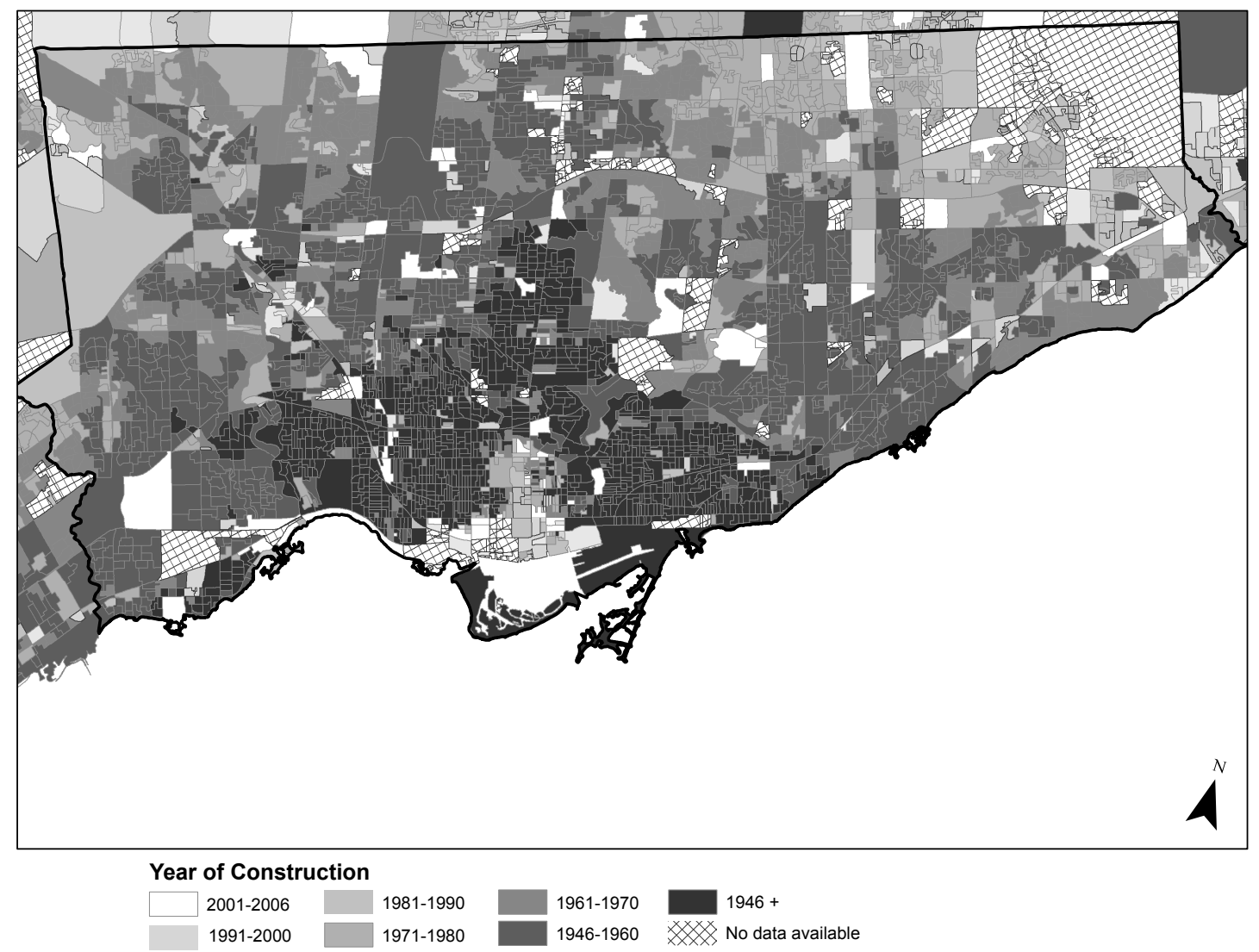

Figure 14: Period of Construction Map. R. Lister, 2018.

This map shows in black the streetcar suburbs built before 1946. The map indicates that Toronto has developed over time in a generally contiguous concentric pattern. Pockets of substantial redevelopment can be seen in the downtown core. Some DAs did not contain sufficient data and are shown in cross-hatching. The area primarily built before 1946 follows the pattern of the Residential (R), Residential Townhouse (RT) and Residential Multiple (RM) 
zoning categories of the City of Toronto, seen in Figure 15 in brown and orange. These areas roughly correspond to the residential parts of the former City of Toronto before amalgamation.

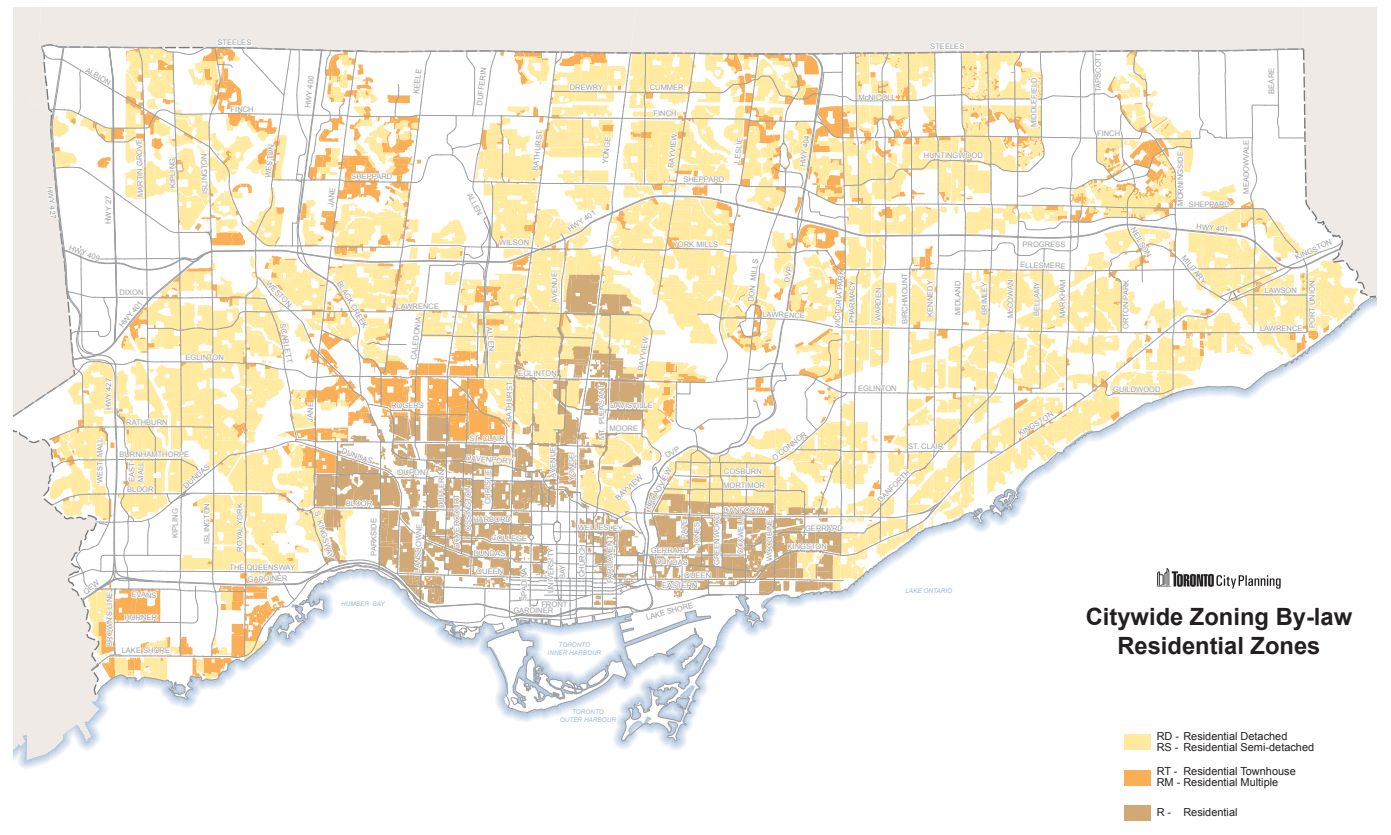

Figure 15: City of Toronto Residential Zones Map.

\subsection{Missing Middle Housing in Toronto}

The idea of constructing more Missing Middle Housing in Toronto has gained attention in recent years in part because it fits the neighbourhood scale of Toronto while increasing density and may provide more affordable home-ownership options (Burda et al., 2016). However, in Figure 16 we can see a limited catalogue of the forms Missing Middle Housing tend to take in Toronto. 


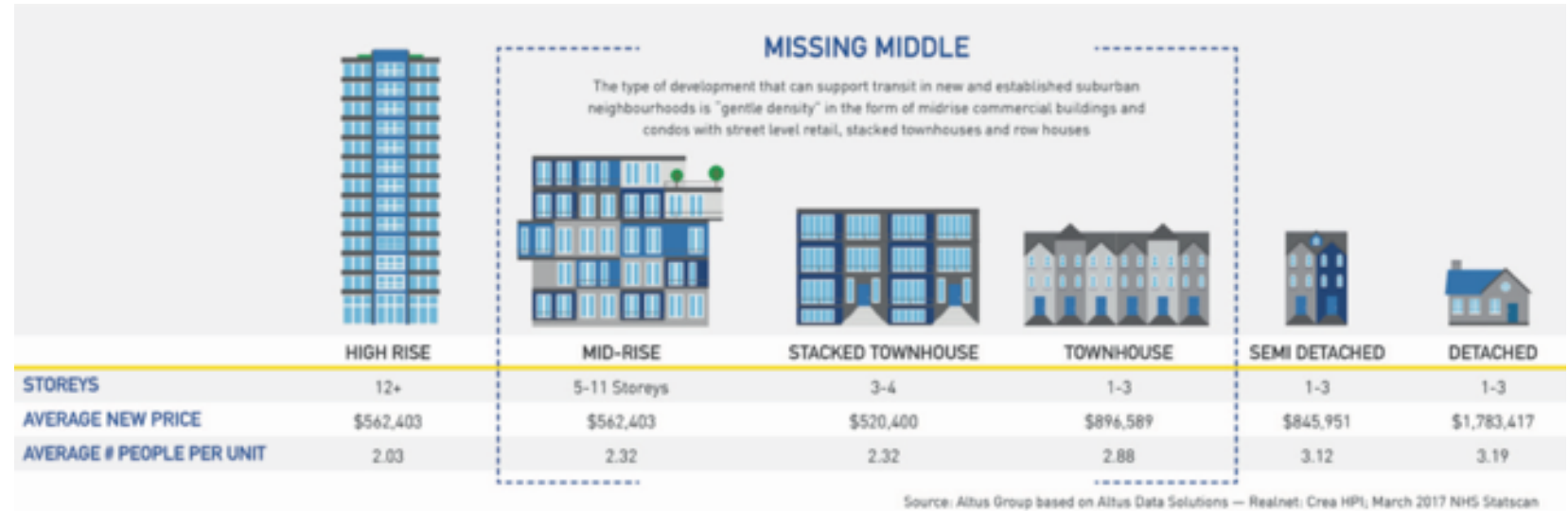

Figure 16: Cost of Missing Middle Housing (Source: Burda et al., 2016; Data from Altus Group, 2016).

Missing Middle Housing within these zoning categories associated with period of construction data are shown in Figure 17. This map forms the basis of my analysis, and features the 3D massing data of all buildings in Toronto that are residentially zoned and between 12 and 36 meters in height. This map confirms that Missing Middle Housing has clustered around the downtown core (Gibson, 2014) and is generally found within the former City of Toronto.

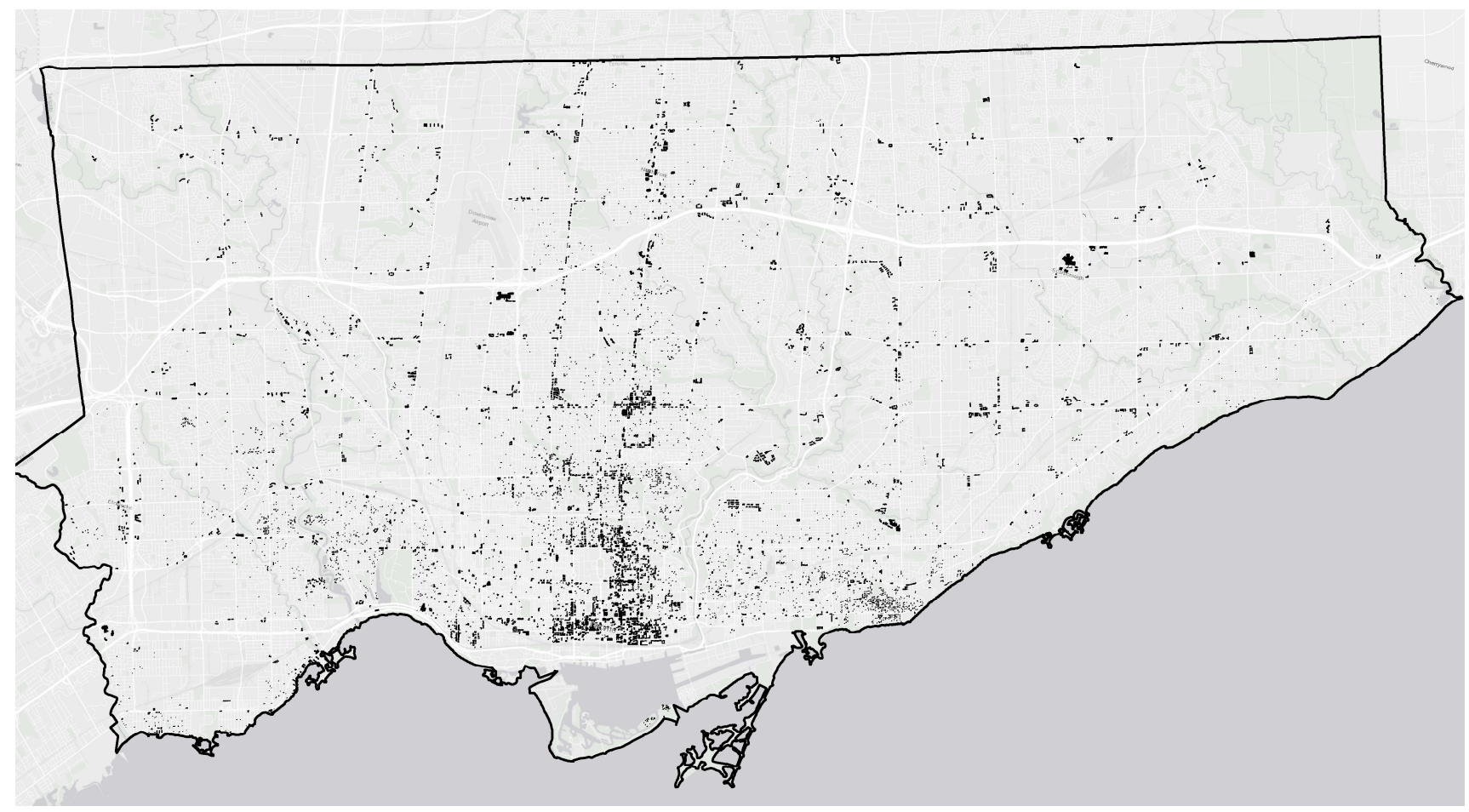

Figure 17: Map of Toronto's Missing Middle Housing, R. Lister, 2018. 
Using this data, I have produced information about the general qualities of Missing Middle Housing in Toronto.

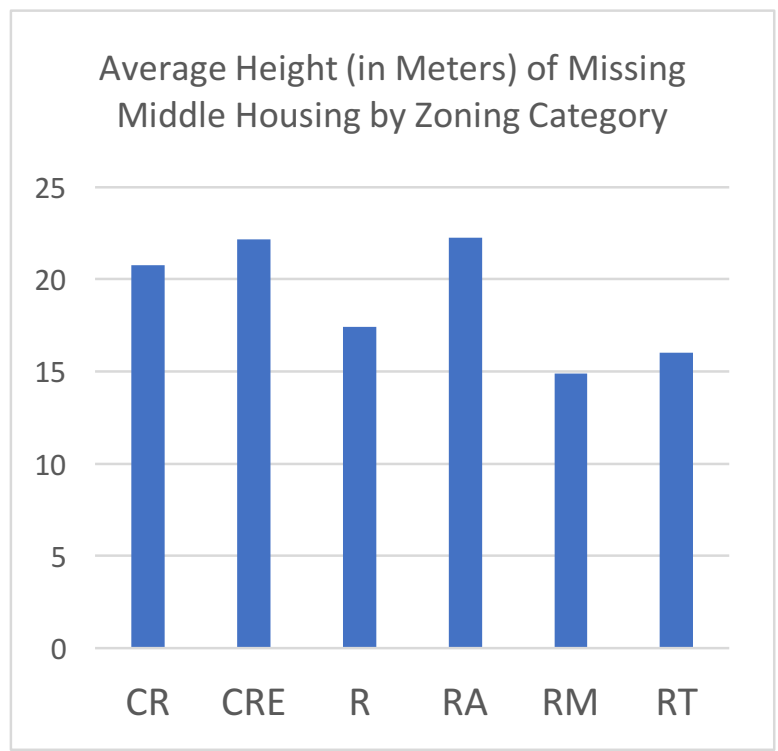

Figure 18: Average Height of Missing Middle Housing in Toronto by Zoning Category. R. Lister, 2018.

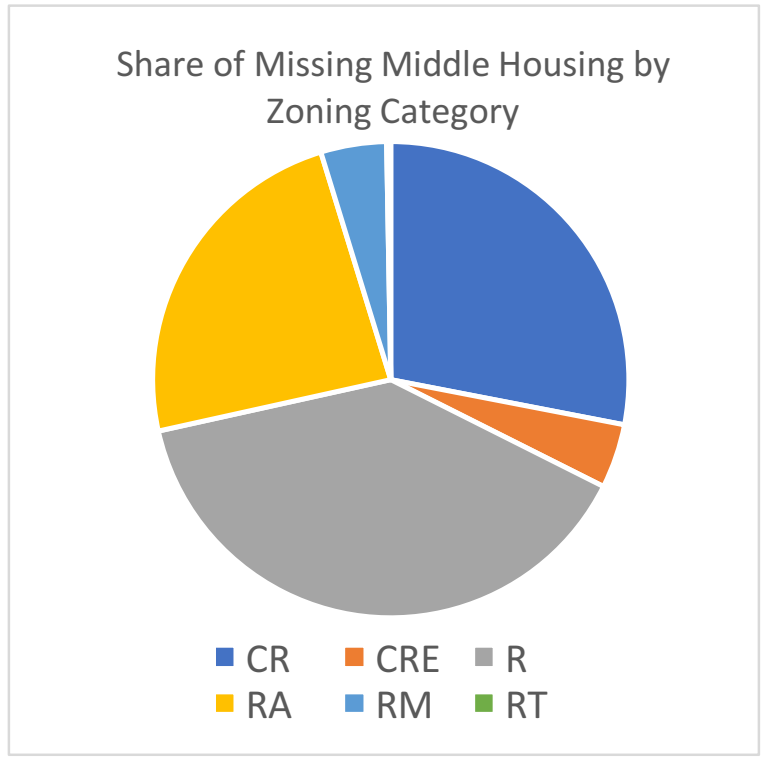

Figure 19: Share of Missing Middle Housing properties in Toronto by Zoning Category. R. Lister, 2018.

As shown in Figure 19, Missing Middle Housing structures are most often found in a Residential zone (39\%), followed by those in a Commercial Residential zone (28\%), and Residential Apartment zone (24\%). The average height of Missing Middle Housing is also different

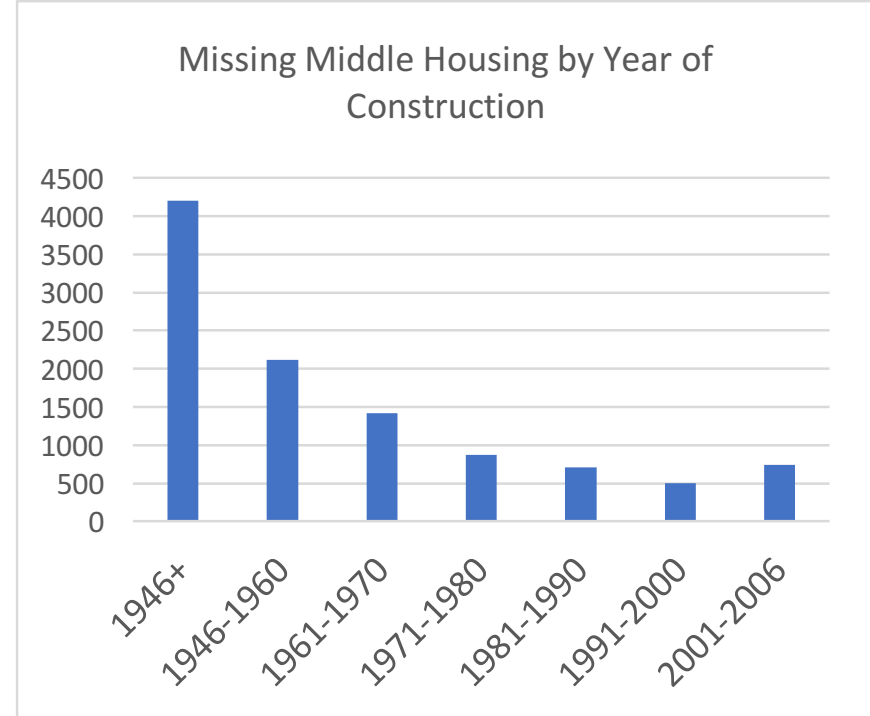

Figure 20: Missing Middle Housing in Toronto by Year of Construction. R. Lister, 2018. depending on the zoning category. Figure 18 indicates that Missing Middle Housing in the Residential Apartment zone is, on average, 22.25 meters high, while those in the Commercial Residential Employment zoning category are the second highest on average at 22.17 meters.

This dataset also confirms that Missing Middle Housing construction has been in decline since the 1940s, as shown in Figure 20. Renewed interest in this type of 
R. Lister - Missing Middle Housing in Toronto: Past \& Present Forms - 2018

housing is evidenced by the uptick in construction in from 2001 to 2006.

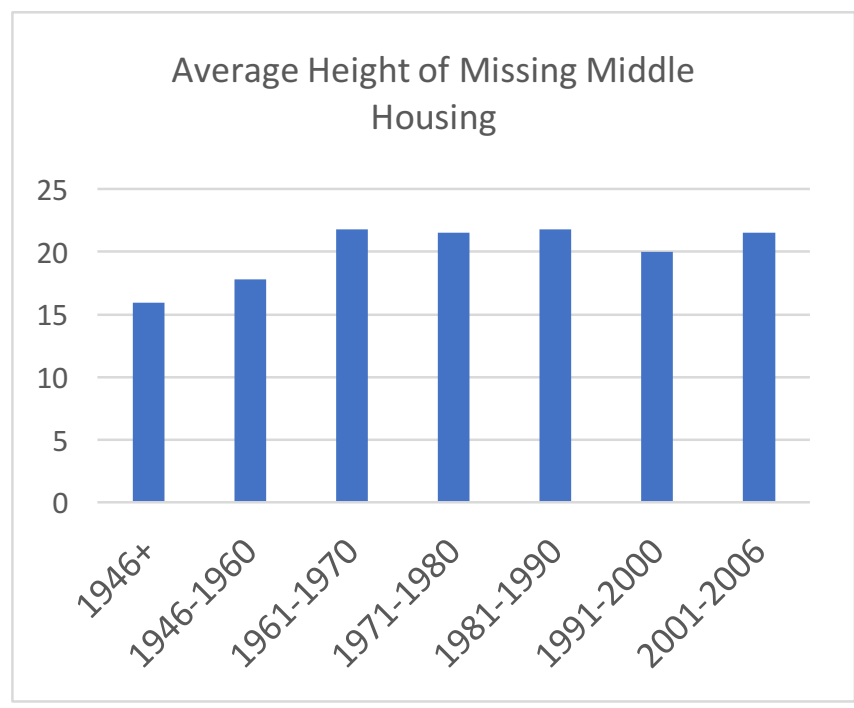

Figure 21: Average Height of Missing Middle Housing in Toronto by Year of Construction. R. Lister, 2018.
While construction of Missing Middle Housing has become less prevalent over time, the average height of these forms has increased since the 1940s (Figure 21). For example, Missing Middle Housing built in the 1961-1970 era has an average height of 21.79 meters. These are most likely due to a boom in rental apartments in the 1960s (Hess \& Sorensen, 2014). 


\subsection{Missing Middle Housing Typologies}

The following Missing Middle Housing typologies were selected following a review of eight study areas. Maps of these areas are contained in Appendix A. The typologies are modeled on real examples of the built form found through this research, and they represent alternatives to the design of Missing Middle Housing most prevalent in recent years. They have been selected by decade of construction.

\subsection{Residential Apartments, Pre-1946}

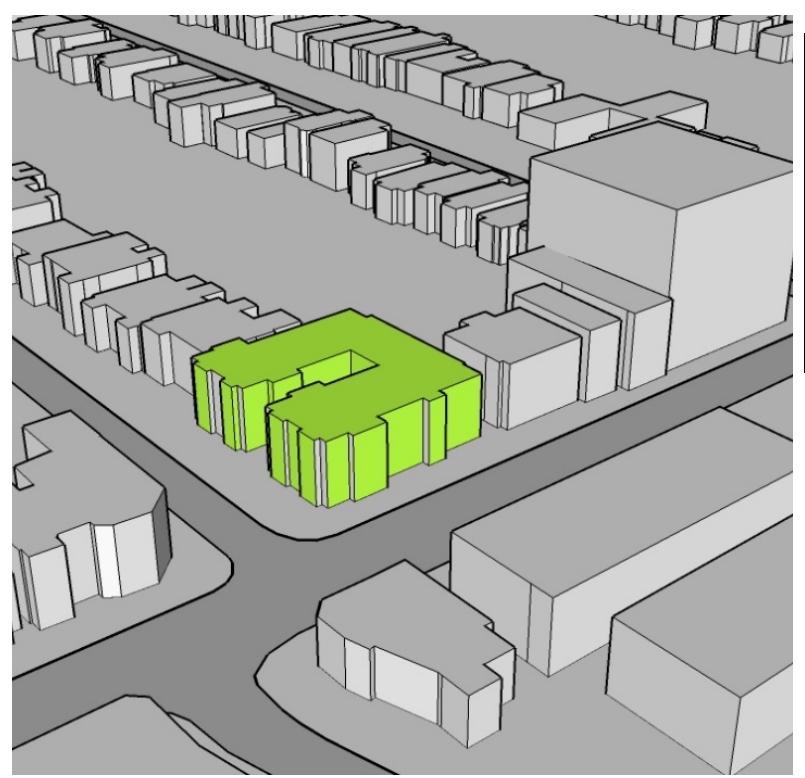

Figure 22: Residential Apartments, Pre-1946 era of construction.

\begin{tabular}{|l|l|}
\hline Zoning Category & Residential (R) \\
\hline Number of Storeys & 4 \\
\hline $\begin{array}{l}\text { Estimated Number } \\
\text { of Units }\end{array}$ & 48 \\
\hline Parking & None \\
\hline
\end{tabular}

Corner sites are most typically found to accommodate apartments of the pre-war era because these sites were exempt from a 1912 by-law passed to increase green space requirements of multi-unit residences (Dennis, 1998). This by-law impacted Toronto's Missing

Middle Housing design. In part because of this by-law and in part because of the era of design, Toronto's Missing Middle contains 4-storey courtyard apartments fronting both residential streets and Avenues. This height is typical of pre-war walkup apartments, which Figure 21 shows to be typically shorter in height than housing built in subsequent decades. This 4-storey typology allowed for wood frame construction, which kept construction costs low. The height allows this typology to fit into residential neighbourhoods dominated by semi-detached houses. 
The courtyard lends greenspace as well as pleasant view corridors and it allows access to sunlight for many units. The typology is modelled on examples of housing found near Avenues. In this typology, the courtyard is facing a residential side street on a corner lot. This positioning changes the setback of the building, depending on the roadway it fronts upon. While facing a residential street, the setback is approximately 10.5 meters, aligning it with the semi-detached homes beside. When fronting an avenue, the setback is 0 meters. This mid-block Avenue orientation is typically found to have a smaller overall lot size, and the size of the courtyard is smaller as a result.

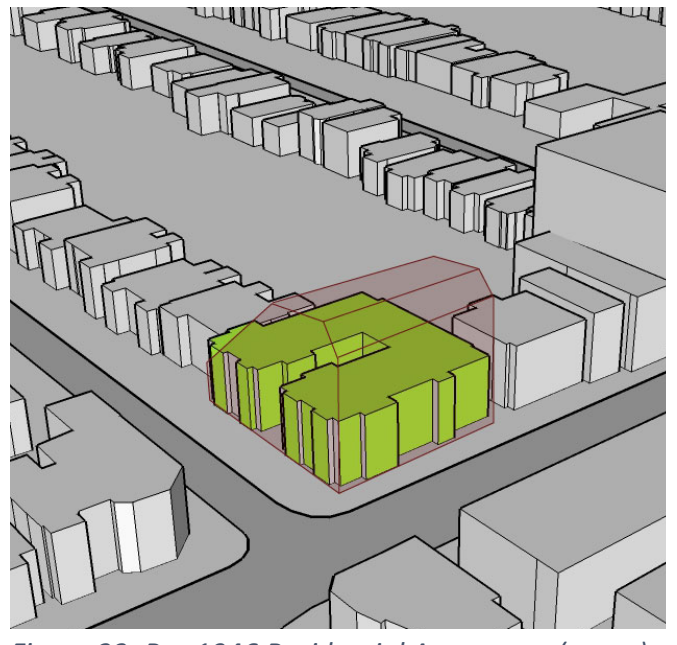

Figure 23: Pre-1946 Residential Apartment (green) with an approximate mid-rise guideline massing overlay (in red).
This typology could not be built along Toronto's avenues today because it is not in keeping with the Performance Standards for Mid-Rise Buildings. Substantial courtyards are discouraged in order to promote a continuous streetwall, and significant terracing would be encouraged along the side of the building facing residential neighbours. Yet we can see that Figure 22 fits into the neighbourhood context well and provides an estimated 48 units of residential density in the space of approximately two singledetached residences. Additionally, the use of the building would likely have to be commercialresidential as opposed to residential. 


\subsection{Residential Apartments, 1946-1960}

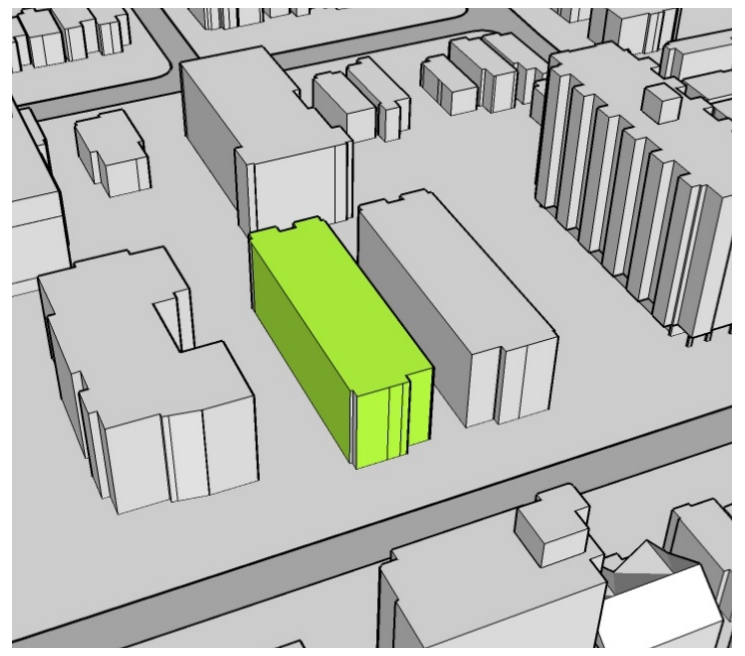

Figure 24: Residential apartment typology, 1946-1960 era of construction.

\begin{tabular}{|l|l|}
\hline Zoning Category & Residential (R) \\
\hline Number of Storeys & $5-6$ \\
\hline $\begin{array}{l}\text { Estimated Number } \\
\text { of Units }\end{array}$ & 60 \\
\hline Parking & Above-Ground \\
\hline
\end{tabular}

This building typology is based on 5-6 storey buildings in areas developed from 1946 to 1960. By the end of this period, buildings were typically taller in response to lot coverage regulations and demand for downtown apartments (White, 2016).

These buildings typically have modest balconies facing the property's frontage. The setback is more or less in line with pre-1940s single- or semi-detached residential buildings along the same streets. On corner lots, the setback remains consistent with the other buildings on the residential street frontage. There is no setback on the side of the property that faces a main street. This pattern of designing and placing buildings in ways that are sensitive to the differences of main streets (including now designated Avenues) and residential streets continues to the present day. Although the buildings do not have a stepback, they fit into the scale of Toronto's residential neighbourhoods and are found sometimes adjacent to single or semi-detached 2-3 storey homes.

The building footprint for this typology is typically rectangular and close to nearby buildings, meaning lot coverage is maximized. However, toward the end of this period of construction, Toronto's planning staff reviewed the residential zoning bylaw to increase setbacks for green space and parking (White, 2016). Parking appears to be absent or minimal and is located at the rear of the buildings above ground. The buildings of this typology often had rear parking shared with neighbouring apartment buildings. This approach maximizes a limited amount of parking 
stalls and indicates a residential apartment development boom in the era. In this period, residential apartments represented $44.7 \%$ of housing constructed within the GTA (Hess \& Sorensen, 2014).

This building typology could not be built on Toronto's avenues under the current mid-rise guideline. Below-ground parking would likely be required, as would a commercial ground floor. The width of the lot would pose a challenge to the suggested massing, but assembling the lot with a neighbouring lot would be very costly.

\subsection{Residential Apartments, 1970s}

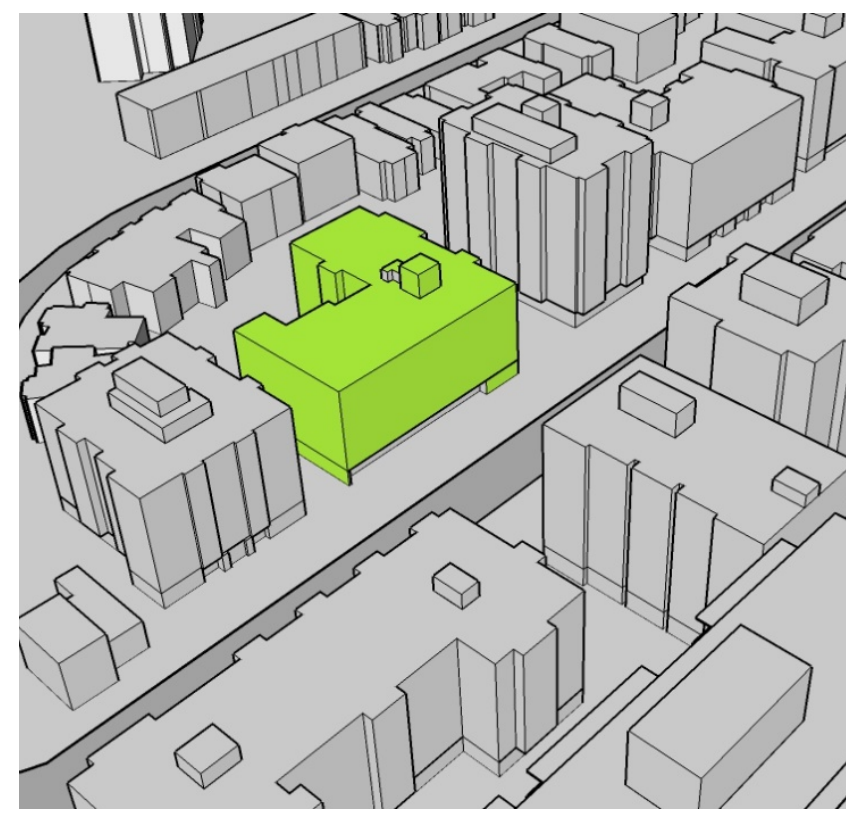

Figure 25: Residential apartment typology, 1970s era of construction.

\begin{tabular}{|l|l|}
\hline Zoning Category & Residential (R) \\
\hline Number of Storeys & 7 \\
\hline $\begin{array}{l}\text { Estimated Number } \\
\text { of Units }\end{array}$ & 90 \\
\hline Parking & $\begin{array}{l}\text { Above- and Below- } \\
\text { Ground }\end{array}$ \\
\hline
\end{tabular}

Buildings of this typology are typically 6-7 storeys, and my research shows that the average height of Missing Middle Housing in this decade was the tallest on average at 21.78 meters. This typology's balconies are more generously sized than previous decades, and units are relatively large in this era of construction.

In my study areas, I did not observe any Missing Middle housing of this era adjacent to single or semi-detached houses. This is not because the scale of this typology is incompatible with lowrise buildings, but because land assembly strategies of the late 1960s were very aggressive (White, 2016) and laid the groundwork for a major apartment construction boom in the 1970s, 
accounting for $50.2 \%$ of housing constructed in the Greater Toronto Area (Hess \& Sorensen, 2014).

There are typically above- and below-ground parking lots available to tenants, with access from an arterial road. The lot coverage pattern allows for more street-facing balconies. Lot coverage appears to be minimized for a more generous setback to allow for grass and landscaping as well as rear parking. These front setbacks are often underutilized green spaces (White, 2016).

Building footprints are less standardized along blocks primarily constructed in this era. Planners

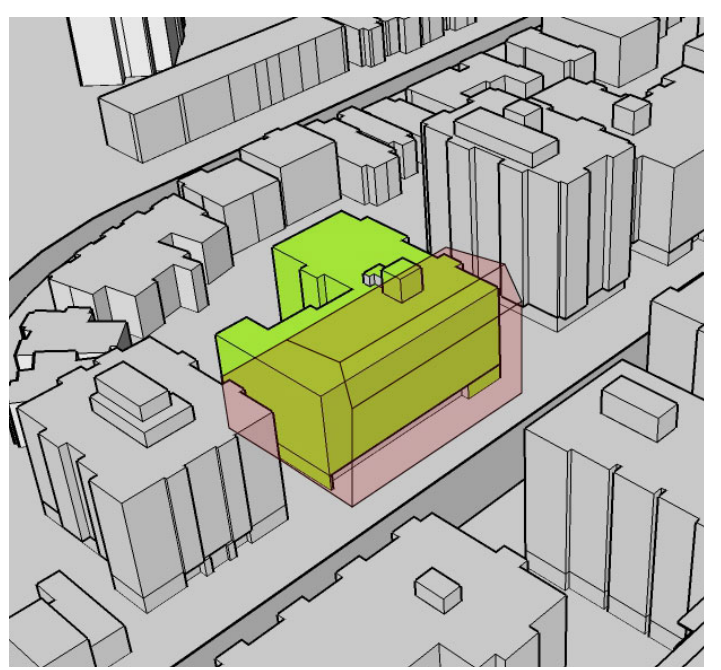

Figure 26: Residential apartment with an approximate mid-rise guideline overlay. of the late 1960s and 1970s felt that nothing was as important as adequate daylight, space and air, and these setbacks and parking regulations are a direct result of that ideology, enforced by a residential bylaw enacted in 1958 (White, 2016).

Unlike the typology from the $1946-1960$ era, this lot could support a building that conforms with current Performance Standards for Mid-Rise Buildings.

Commercial use at ground level would be preferred, the continuous street wall would be maintained as would below-ground parking. The mid-rise guideline massing would bring the building typology closer to the property line, and angular planes would change the appearance of building height from the pedestrian realm. However, this re-massing could possibly preserve the residential density of the building, perhaps with an additional one to two storeys. 


\subsection{Commercial-Residential Apartments, 1980s}

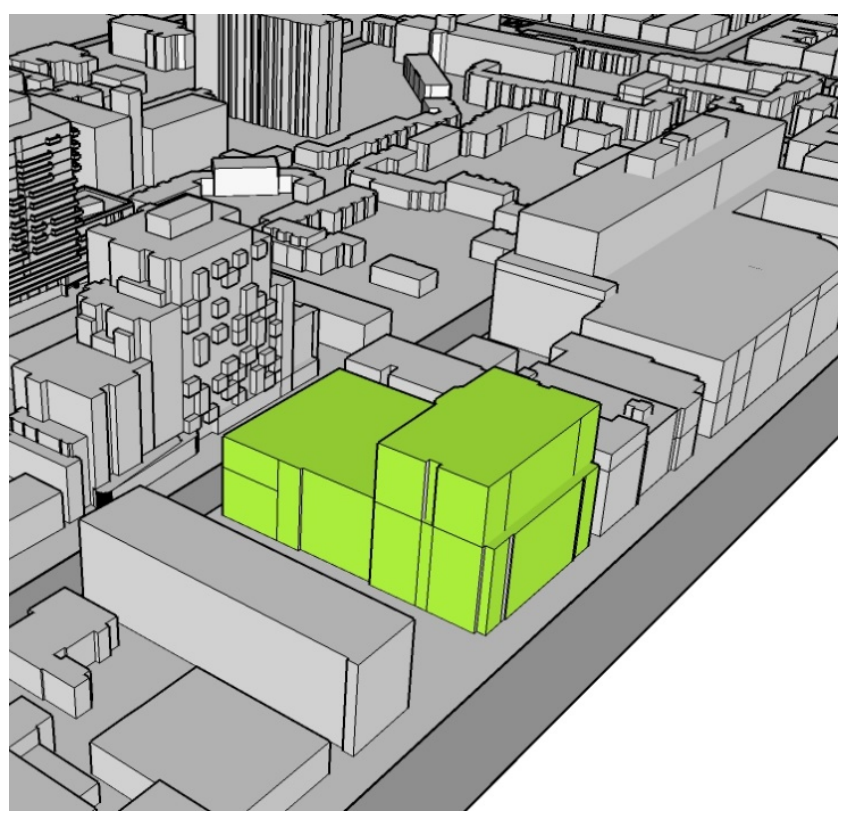

Figure 27: Commercial-residential apartments, 1980s era of construction.

\begin{tabular}{|l|l|}
\hline Zoning Category & $\begin{array}{l}\text { Commercial } \\
\text { Residential (CR) }\end{array}$ \\
\hline Number of Storeys & $9-10$ \\
\hline $\begin{array}{l}\text { Estimated Number } \\
\text { of Units }\end{array}$ & 126 \\
\hline Parking & $\begin{array}{l}\text { Above- and Below- } \\
\text { Ground }\end{array}$ \\
\hline
\end{tabular}

Toronto has a strong history of apartments over retail storefronts along Avenues. This typology builds upon that history within the commercial residential zoning designation. Ground-level retail with a generous height enlivens the commercial corridor while nine storeys of residential use allow the building to maximize its floor space allowance. Sorensen \& Hess (2014) noted that the share of strictly residential land uses have been in decline in the Greater Toronto Area since the 1961-1970 period. Most importantly, the 1976 Central Area Plan limited commercial building outside the financial district to low- and mid-rise buildings, and encouraged mixed-use residential building by allowing higher densities for such projects (White, 2016). The outcome of this plan is seen in this mid-rise commercial-residential typology. There are minimal stepbacks in the massing of this typology, and balconies are minimal, usually appearing at the corners of the residential frontage only.

Onsite parking is found above ground for commercial uses and inside the building for residents. Internal residential parking is accessed from a laneway behind the building. This configuration is largely due to the regulations of the 1976 Central Area Plan, which put a priority on continuity of streetscape and especially streetline (McHugh, 1989). Examples of this typology were found 
along a transit corridor, and represent fairly dense Missing Middle Housing that incorporates green space while maintaining a consistent street wall.

This typology's massing would not conform with current mid-rise guidelines, though the width and depth of this lot could accommodate changes to the typology. Significant stepbacks could be supported to accommodate the mid-rise guideline angular plane, and this would shift the massing of the residential units, bringing them further away from the street. This change would make the green roof currently on top of the podium of the building unlikely, meaning residents would not have access to green space.

\subsection{Residential Apartments, 1990s}

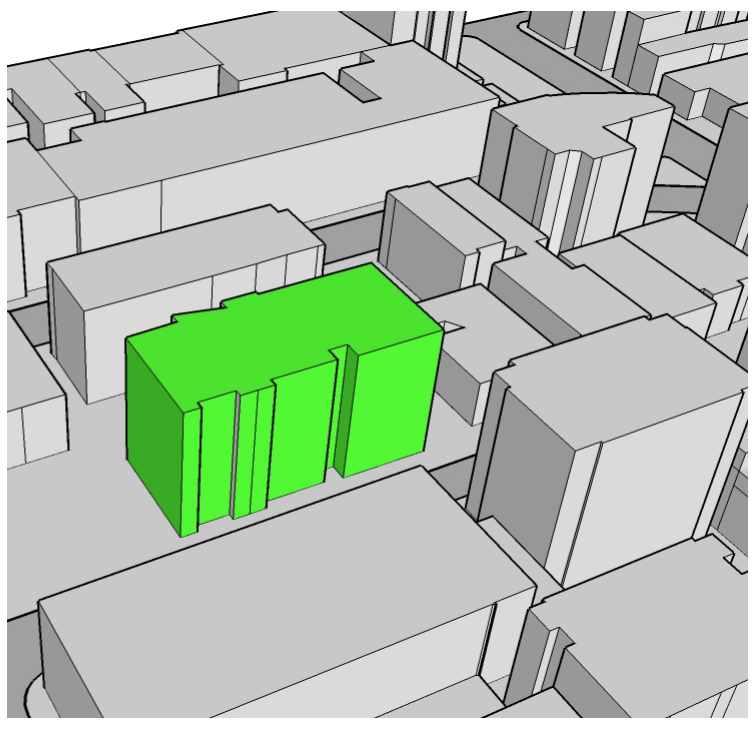

Figure 28: Residential apartment typology, 1990s era of construction.

\begin{tabular}{|l|l|}
\hline Zoning Category & Residential (R) \\
\hline Number of Storeys & 10 \\
\hline $\begin{array}{l}\text { Estimated Number } \\
\text { of Units }\end{array}$ & 80 \\
\hline Parking & Below-Ground \\
\hline
\end{tabular}

around 10 storeys in height with no stepbacks and few balconies. The massing of the building maximizes lot coverage and follows the trend of the 1980s typology in having no setback from the

street it fronts upon, allowing for a consistent streetline. It was difficult to find a wide array of residential Missing Middle housing of this period within my study areas, since fewer Missing Middle housing properties were constructed during this decade in Toronto. Instead, apartment buildings were increasing in height and accounted for only $13.9 \%$ of housing built in the Greater Toronto Area at that time (Sorensen \& Hess, 2015). 
Underground parking access is located at the building's frontage in this mid-block typology. This typology is an example of Missing Middle housing that maximizes its position in the urban area by covering the majority of the lot. It is dense and compact in its massing, while its height makes it an appropriate typology for Toronto's avenues. The current Mid-Rise Building Performance Standards would encourage commercial use on the ground level of this building, as well as substantial terracing of the back of the building. This would decrease the residential density of this typology. See Figure 29 for an approximate mid-rise guideline massing overlay.

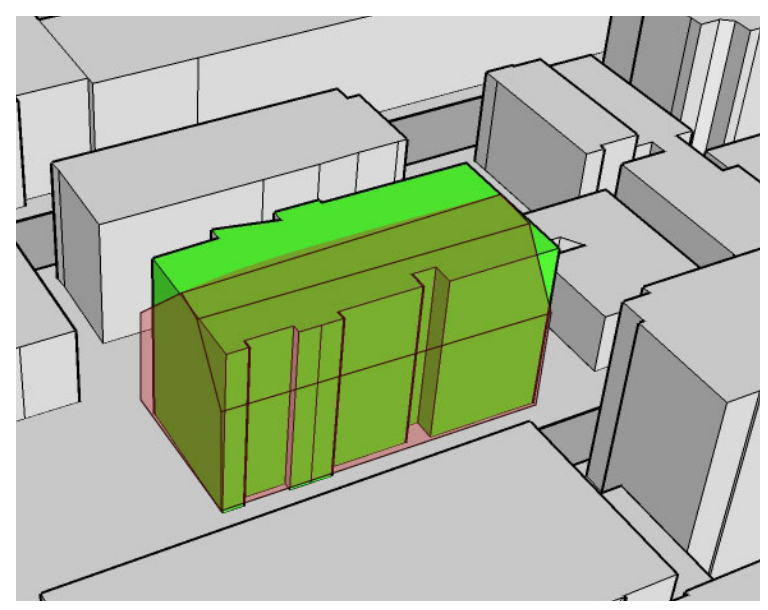

Figure 29: Residential Apartment, 1990s construction with approximate mid-rise massing overlay in red.

\subsection{Commercial-Residential Apartments, 2000s}

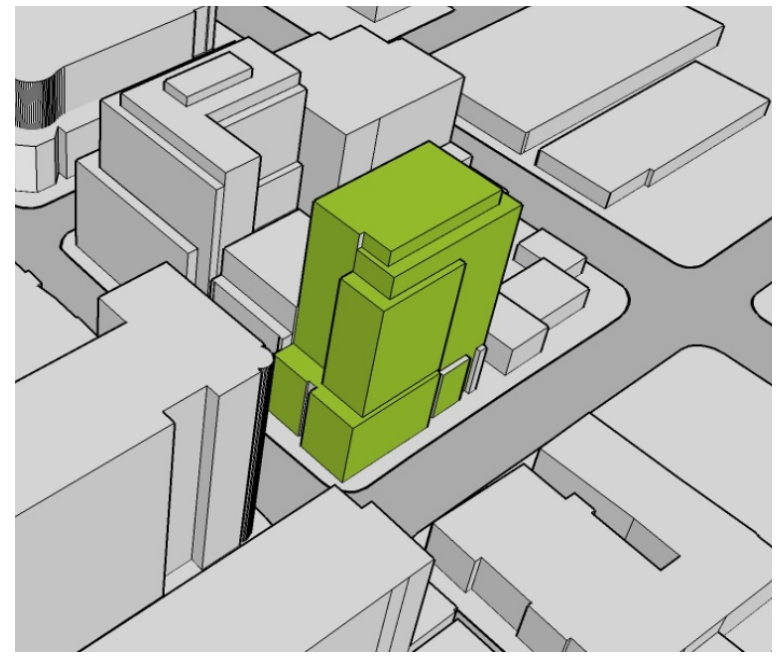

\begin{tabular}{|l|l|}
\hline Zoning Category & $\begin{array}{l}\text { Commercial } \\
\text { Residential (CR) }\end{array}$ \\
\hline Number of Storeys & $10-11$ \\
\hline $\begin{array}{l}\text { Estimated Number } \\
\text { of Units }\end{array}$ & 150 \\
\hline Parking & Below-Ground \\
\hline
\end{tabular}

The Commercial-Residential Apartments of the 2000s are also drawn from a smaller sample size 
than typologies of previous decades. This typology shows the beginning of required stepbacks, a measure intended to lessen the impression of height when viewed at the pedestrian level. This element allows such a typology to fit in along Toronto's avenues closest to the downtown core or growth areas.

The commercial use occupies the ground level, while the remaining storeys appear to be residential. This typology is a building 10-11 storeys in height, located on a corner lot. The massing of the building maximizes lot coverage, meaning it follows the trend of 1990s typology in terms of increased residential density. This typology has a number of balconies above the setback, which is a selling feature for condominiums. The massing suggestions of the current mid-rise building guideline would substantially change the massing of this typology and decrease the residential density as a result.

\subsection{Commercial-Residential Apartments, 2010s}

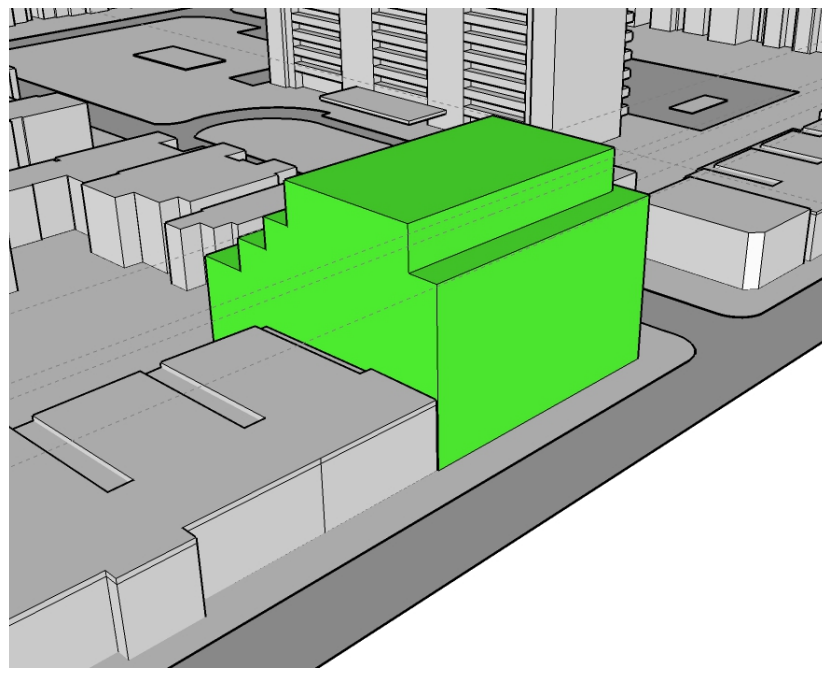

Figure 31: Commercial-residential apartment typology, 2010s era of construction.

\begin{tabular}{|l|l|}
\hline Zoning Category & $\begin{array}{l}\text { Commercial } \\
\text { Residential (R) }\end{array}$ \\
\hline Number of Storeys & 7 \\
\hline $\begin{array}{l}\text { Estimated Number } \\
\text { of Units }\end{array}$ & 51 \\
\hline Parking & Below-Ground \\
\hline
\end{tabular}

My final typology is a commercial-residential apartment of the 2010s. It is a seven-storey building on a corner lot. In keeping with other commercial-residential typologies, the ground level is occupied by a commercial

use. There is a stepback after the fifth storey and the massing is reminiscent of the Performance Standards for Mid-Rise Buildings. There is a slightly more generous setback along the avenue than I observed in other typologies, allowing the public realm to be widened at the sidewalk level. This typology is typically found along Toronto's Avenues, though few such buildings have 
been constructed because of the challenging economics of mid-rise development at present (Brown, 2012). Burda et al., (2017) have shown there has been a slight increase in buildings under 12 storeys in the pre-construction or construction phase within the City of Toronto, meaning we are likely to see more examples of this typology as time goes on.

\subsection{Typologies Compared}

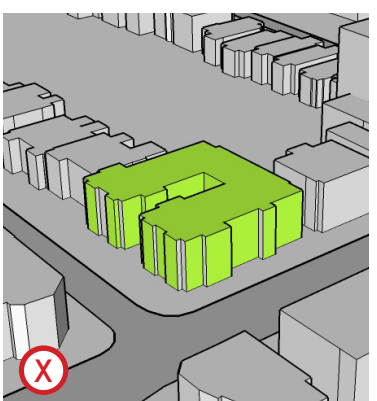

Residential Apartments, Pre-1946

Storeys: 4

Estimated Units: 48

Parking: None

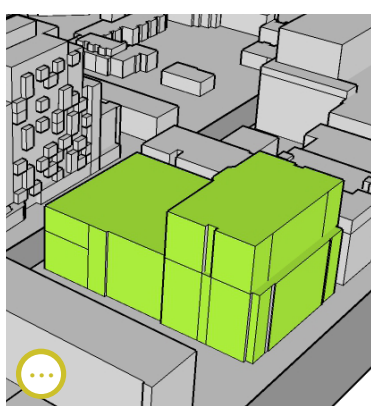

Commercial-Residential Apartments, 1980s Storeys: $9-10$

Estimated Units: 126

Parking: Above- and Below-Ground

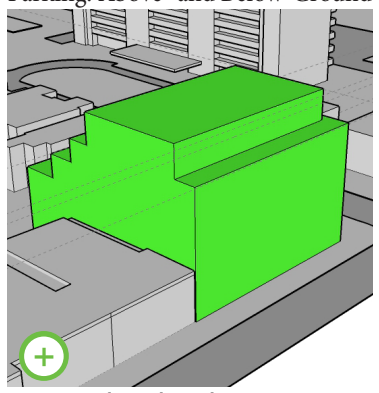

Commercial-Residential Apartments, 2010s

Storeys: 7

Estimated Units: 51

Parking: Below-Ground

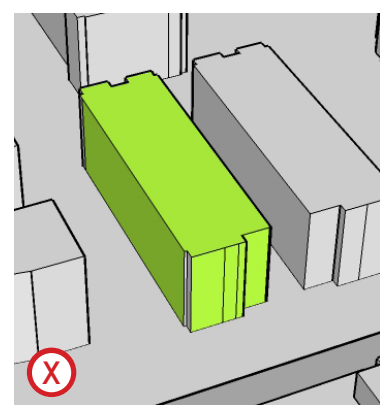

Residential Apartments, 1946-1960 Storeys: 5-6

Estimated Units: 60

Parking: Above-Ground

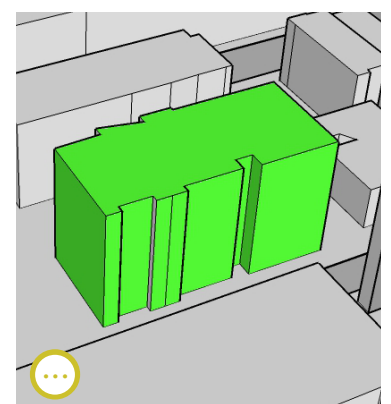

Residential Apartments, 1990s Storeys: 10

Estimated Units: 80

Parking: Below-Ground

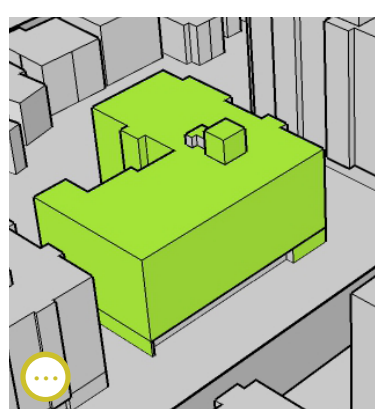

Residential Apartments, 1970s

Storeys: 7

Estimated Units: 90

Parking: Above- and Below-Ground

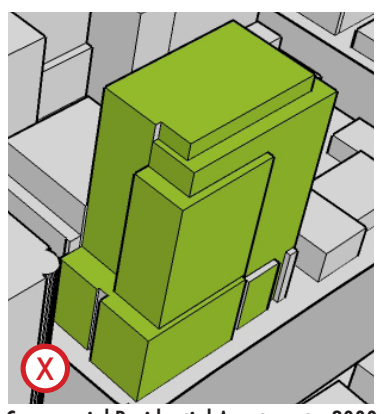

Commercial-Residential Apartments, 2000s

Storeys: 10-11

Estimated Units: 150

Parking: Below-Ground

LEGEND: Conformity with Mid-Rise Performance Standards (2010)

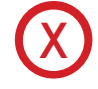

Does not conform

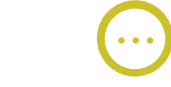

Alteration to setback or stepbacks required

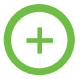

Conforms

Figure 32: Missing Middle Housing typologies comparison chart. R. Lister, 2018. 
This research paper has by no means presented an exhaustive catalogue of past and present forms of Missing Middle Housing in Toronto. However, it does illustrate some of the many ways to provide Missing Middle Housing between 4 and 11 storeys. As evidenced by Figure 32, these typologies often do not conform with the City of Toronto's Mid-Rise Building Performance Standards (2010). In the case of the Pre-1946 typology, substantial courtyard setbacks would not be allowed under the new Performance Standards (2010), as they encourage a uniform streetline. This feature, however, can increase access to sunlight for units and provide greenspace alongside building access points. Other typologies, such as the Residential Apartment of the 1970s, could be modified with stepbacks to achieve the 45-degree angular plane suggested by the 2010 Performance Standards. Modifications to this typology's built form could be accommodated without significant loss of density because of substantial lot size. Other typologies, such as the Commercial-Residential Apartment of the 2000s could not be modified to achieve the 45-degree angular plane suggestions without a substantial loss of residential density. In such a case, these guidelines would encourage a developer to increase the height of the project in order to maximize density. A height increase would allow the building to come under the City of Toronto's Tall Building Design Guidelines (2013), which do not require substantial terracing.

This major research paper may serve as a reminder to look beyond the form suggested by the City of Toronto's Mid-Rise Building Performance Standards towards alternate typologies that may be more appropriate for different lot dimensions or different area contexts throughout Toronto. More flexibility with regard to building design can allow for greater residential density, which in turn could result in more development of Missing Middle Housing in Toronto. Given the polarization of Toronto's development landscape, the Missing Middle represents an opportunity to provide more ground-related units within or adjacent to Toronto's many neighbourhoods. The benefits of Missing Middle Housing are plentiful: they provide more affordable ownership options than single- or semi-detached homes, helping to keep Toronto's neighbourhoods vibrant (Burda et al., 2017); they capitalize on existing transit infrastructure to promote sustainable and walkable development (Miller et al., 2010) and they can benefit from 
R. Lister - Missing Middle Housing in Toronto: Past \& Present Forms - 2018

environmentally-friendly building practices (Gibson, 2014). Overall, Missing Middle Housing development can provide Toronto with an opportunity to develop greater residential density in a location-efficient way while preserving the City's unique neighbourhood character. Allowing for a diversity of Missing Middle Housing forms can help increase the amount of Missing Middle Housing development in Toronto. 


\subsection{Recommendations and Conclusion}

This research has shown that a range of typologies of Missing Middle housing exist in Toronto, though they have not been built in great number in the decades following 1946. These typologies originate in different eras of construction, and illustrate expanded possibilities for Missing Middle housing that supports transit, promotes walkability and increases density along Toronto's Avenues or even within stable residential neighbourhoods. While the City of Toronto's planning policies have been characterized by conservative, incremental change, these policies have also emphasized the protection of heritage and character (White, 2016). With that in mind, understanding the forms of Missing Middle housing that have existed in Toronto and helped to shape the character of the city's built form is an important step in supporting the creation of more Missing Middle housing. This major research paper has illustrated some examples of such housing and noted some design elements and policy constraints that have shaped these forms.

The City of Toronto has produced Performance Standards for Mid-Rise Buildings (2010) to promote a particular typology of Missing Middle housing along Toronto's Avenues. These guidelines present a limited idea of appropriate design for the Toronto context. As we can see, Toronto contains numerous approaches to Missing Middle Housing design that also accomplish the goals of increasing density while fitting with the built form context. The mid-rise guideline constrains the massing of new buildings in order to preserve view corridors and maximize access to sunlight and privacy for neighbouring residential buildings. These are positive design features that should be celebrated. However, these guidelines contribute to the challenges facing mid-rise economic feasibility in Toronto (Miller et al., 2010).

The City of Toronto has taken measures to address the feasibility constraints some regulations place on developers of Missing Middle Housing. City Council will receive a staff report on the implications of exempting low-rise apartment buildings from parking requirements in the second quarter of 2018 (City of Toronto, 2018). This could result in more affordable 
construction cost per unit in such buildings, and is an important step toward encouraging residents to forgo car ownership along transit corridors.

The length and uncertainty of the approvals process has been noted by municipal and developer stakeholders as one of the top three factors negatively impacting the feasibility of mid-rise housing in Ontario (Miller, 2010). To address this concern, future measures that the City of Toronto may wish to explore include re-zoning Toronto's avenues to support a height of 4 to 11 storeys. This would likely result in a shorter approvals process for developers of Missing Middle Housing, and in turn it would allow new units to reach the market at a faster pace. Another means of addressing this issue could involve fast-tracking Missing Middle Housing development applications. The City of Toronto already fast-tracks affordable housing applications through the Affordable Housing Office's Open Door Program (City of Toronto, 2017). A similar commitment to Missing Middle Housing, coupled with flexible parking requirements, could lower the cost of development and therefore incent developers to produce more of these forms.

This major research paper has begun the work of providing illustrations of different typologies of Missing Middle Housing in Toronto, many of which do not conform to the current Performance Standards for Mid-Rise Buildings (2010). I have argued that allowing more design flexibility would allow for more types Missing Middle Housing to be built in Toronto. Different typologies will be able to respond to different design contexts while increasing residential density near Toronto's neighbourhoods. Furthermore, increasing flexibility of design guidelines is one of the ways that the City can work to address the polarized development landscape we see in Toronto. This action will increase the diversity of housing options while respecting and preserving Toronto's reputation as a city of neighbourhoods. 
R. Lister - Missing Middle Housing in Toronto: Past \& Present Forms - 2018

\section{Sources:}

Beaumont, A. (2012). Barriers to mid-rise development in suburban communities in the Greater Toronto Area (Major Research Paper). Ryerson University, Toronto, ON.

Bedford, P. (2013). Unlocking the potential for mid-rise buildings: six storey wood structures. Prepared for the Building Industry and Land Development Association.

Blais, P. (2010). Perverse cities: hidden subsidies, wonky policy, and urban sprawl. Vancouver: UBC Press.

Brown, R. (2012). Barriers to Mid-Rise Development in Toronto (Major Research Paper). Ryerson University, Toronto, ON.

Burda, C. (2013). Priced out: Understanding the factors affecting home prices in the GTA. Toronto: Pembina Institute. Retrieved from: http://www.pembina.org/reports/pricedout.pdf

Burda, C., Collins-Williams, M. (2015). Make way for mid-rise. Toronto: Pembina Institute Retrieved from: http://www.pembina.org/reports/make-way-for-mid-rise.pdf

Burda, C., Collins-Williams, M., Kingdon, A. (2016). Suburbs on track : Building transit-friendly neighbourhoods outside the Toronto core. Retrieved from:

https://www.ryerson.ca/content/dam/citybuilding/pdfs/2016/REPORT-

Suburbs\%20on\%20Track-September\%207,\%202016.pdf

Burda, C., Haines, G., Hildebrand, S. (2017). Bedrooms in the sky. Retrieved from: https://www.citybuildinginstitute.ca/wp-content/uploads/2017/11/FINALBedroomsInTheSky.pdf

Buxton, M., Tieman, G. (2005). Patterns of urban consolidation in Melbourne: Planning policy and the growth of medium density housing. Urban policy and research, 23(2): 137-157.

Campoli, J., McLean, A. (2002). Visualizing density. Cambridge: Lincoln Institute of Land Policy.

City of Toronto. (2010). Performance Standards for Mid-Rise Buildings. Retrieved from: https://www.toronto.ca/wp-content/uploads/2017/08/960c-Performance-Standards-for-MidRise-Buildings.pdf

City of Toronto. (2013). Tall Building Design Guidelines. Retrieved from: https://www.toronto.ca/wp-content/uploads/2018/01/96ea-cityplanning-tall-buildingsmay2013-final-AODA.pdf 
R. Lister - Missing Middle Housing in Toronto: Past \& Present Forms - 2018

City of Toronto. (2015). Official Plan. Retrieved from:

https://www.toronto.ca/wp-content/uploads/2017/11/99b3-cp-official-plan-volume-1consolidation.pdf

City of Toronto. (2017). Open Door Affordable Housing Program Guidelines. Retrieved from: https://www.toronto.ca/wp-content/uploads/2017/10/96ee-OpenDoorGuidelines-F.pdf

City of Toronto. (2018, March 26). Townhouse and Low-Rise Apartment Guidelines City Council Decision. Retrieved from:

http://app.toronto.ca/tmmis/viewAgendaltemHistory.do?item=2018.PG27.5

De Silva, Jan. (2017, May, 10). Toronto has space for housing. Toronto Star. Retrieved from: https://www.thestar.com/opinion/commentary/2017/05/10/toronto-has-space-forhousing.html

Dennis, R. (1998). Apartment housing in Canadian cities, 1900-1940. Urban history review, 26(2): 17-31.

Filion, P. (2000). Balancing concentration and dispersion? Public policy and urban structure in Toronto. Environment and Planning: Government and Policy, 18(1): 163-189.

Fyall, R., Casey, A. (2017). Urbanizing for equality: Harnessing upzones as a redistributive policy tool. Cityscape: A Journal of Policy Development and Research, 19(2): 9-20.

Haines, G., Aird, B. (2018). Getting intense: Rethinking planning for an intensification-first approach. Retrieved from: https://www.citybuildinginstitute.ca/wpcontent/uploads/2018/03/FINAL-GettingIntense.pdf?mc_cid=7fc3676c37\&mc_eid=e734c73159

Hess, P., Sorensen, A. (2015). Compact, concurrent, and contiguous: Smart growth and 50 years of residential planning in the Toronto region. Urban geography, 36(1): 127-151.

Gibson, G. (2014). Growing Mid-Rise: Evaluating the Potential for Taller Wood Frame Buildings (Major Research Paper). University of Toronto, Toronto, ON.

Intrator, K., and Shivdikar, K. (2017). Missing 'middle scenarios': Uncovering nuanced conditions in Latin America's housing crisis. Cityscape: A journal of policy development and research, 19(2): 31-43.

Kalinowski, T. (2016, September, 7). Growth plan will fill in 'missing middle' of housing choices: report. Toronto Star. Retrieved from: 
https://www.thestar.com/business/real_estate/2016/09/07/growth-plan-will-fill-in-missingmiddle-of-housing-choices-report.html

Keesmaat, J. (2017, December 13). Jennifer Keesmaat: It's time to rethingk Canada's housing system. Maclean's Magazine. Retrieved from: http://www.macleans.ca/opinion/jenniferkeesmaat-its-time-to-rethink-canadas-housing-system/

Kolson Hurley, A. (2016, January, 18). Will U.S. cities design their way out of the affordable housing crisis? Next City. Retrieved from: https://nextcity.org/features/view/cities-affordablehousing-design-solution-missing-middle

Kukutai, T., Thompson, V., McMillan, R. (2014). Whither the census? Continuity and change in census methodologies worldwide, 1985-2014. Journal of Population Research, 32(3): 3-22.

Miller, G., Hunt, M., Myrans, I. (2010). Midrise Symposium 2009: Breaking barriers, building confidence: Making midrise work in Toronto. Retrieved from:

https://static1.squarespace.com/static/546bbd2ae4b077803c592197/t/58c83da1725e25b97bd ea824/1489517992828/CUI_Midrise_Symposium_FINAL.pdf

Moore, A. A. (2000). Planning politics in Toronto: The Ontario Municipal Board and urban development. Toronto: University of Toronto Press.

McDaniel, S., MacDonald, H. (2012). To know ourselves - Not. The Canadian Journal of Sociology, 37(3): 253-271.

McHugh, P. (1989). Toronto architecture: A city guide. Toronto: McClelland \& Stewart.

Parolek, D. (2015). Missing Middle Housing: Responding to the Demand for Walkable Urban Living.

Paulsen, K. (2017). The goldilocks dilemma of moderate-income housing subsidies: Finding the "just right" amount for the missing middle. Cityscape: A Journal of Policy Development and Research, 19(1): 245-251.

Rai, S. (2007). Inhabiting the Terminus: Creating Density in Vaugh Through an Exploration of Mid-Rise, Mid-Density Form and Mass Transit Infrastructure (Masters Thesis). Dalhousie University, Halifax, NS.

Sewell, J. (2009). The shape of the suburbs: Understanding Toronto's sprawl. Toronto, University of Toronto Press.

Solomon, L. (2007). Toronto sprawls: A history. Toronto, University of Toronto Press. 
Sorensen, A., Hess, P. (2014). Building suburbs, Toronto-style: Land development regimes, institutions, critical junctures and path dependence.

Sotomayor, A. (2016). The mid rise challenge: Tools for incentivizing private developers (Major Research Paper). Ryerson University, Toronto, ON.

Statistics Canada. (2011). Housing Reference Guide: National Household Survey, 2011.

Retrieved from: http://www12.statcan.gc.ca/nhs-enm/2011/ref/guides/99-014-x/99-014x2011007-eng.pdf

Statistics Canada. (2018). About Data tables, 2016 Census. Retrieved from: http://www12.statcan.gc.ca/census-recensement/2016/dp-pd/dt-td/Rpeng.cfm?TABID=1\&LANG=E\&A=R\&APATH=3\&DETAIL=0\&DIM=0\&FL=A\&FREE=0\&GC=01\&GL=$1 \& G I D=1257309 \& G K=1 \& G R P=1 \& O=D \& P I D=111830 \& P R I D=10 \& P T Y P E=109445 \& S=0 \& S H O W A L L$ $=0 \& S U B=0 \&$ Temporal $=2017 \&$ THEME $=121 \& \mathrm{VID}=0 \& \mathrm{VNAMEE}=\& \mathrm{VNAMEF}=\& D 1=0 \& D 2=0 \& D 3=0 \&$ $\mathrm{D} 4=0 \& \mathrm{D} 5=0 \& \mathrm{D} 6=0$

Toronto Real Estate Board (2018). TREB Housing Market Charts: March 2018. Retrieve from: http://www.trebhome.com/market_news/housing_charts/index.htm

Tuckey, B. (2017, November, 4). Lack of 'missing middle' housing making GTA's real estate market increasingly unaffordable. Toronto Star. Retrieved from:

https://www.thestar.com/life/homes/2017/11/04/lack-of-missing-middle-housing-makinggtas-real-estate-market-increasingly-unaffordable.html

Weatherburn, T., Davis, W. (2016). [Map illustrating regional population change from 2011 2016, created February 7, 2016]. Population change in the Greater Golden Horseshoe, 20112016. Retrieved from: http://www.mapto.ca/maps/2017/2/7/popchange2016

White, R. (2016). Planning Toronto: The planners, the plans, their legacies, 1940-1980. Vancouver: UBC Press. 
R. Lister - Missing Middle Housing in Toronto: Past \& Present Forms - 2018

\section{Appendix A: Maps}

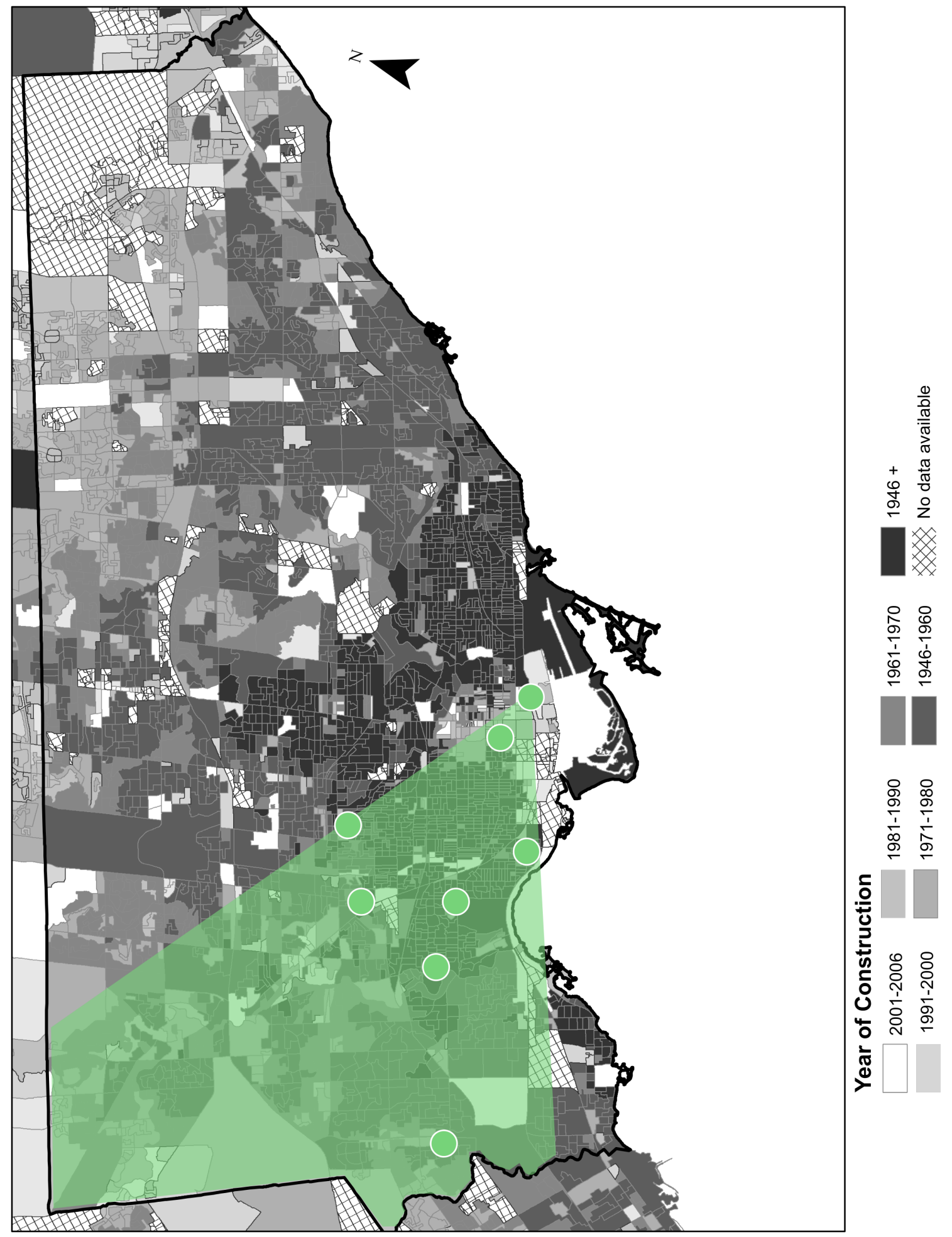


R. Lister - Missing Middle Housing in Toronto: Past \& Present Forms - 2018

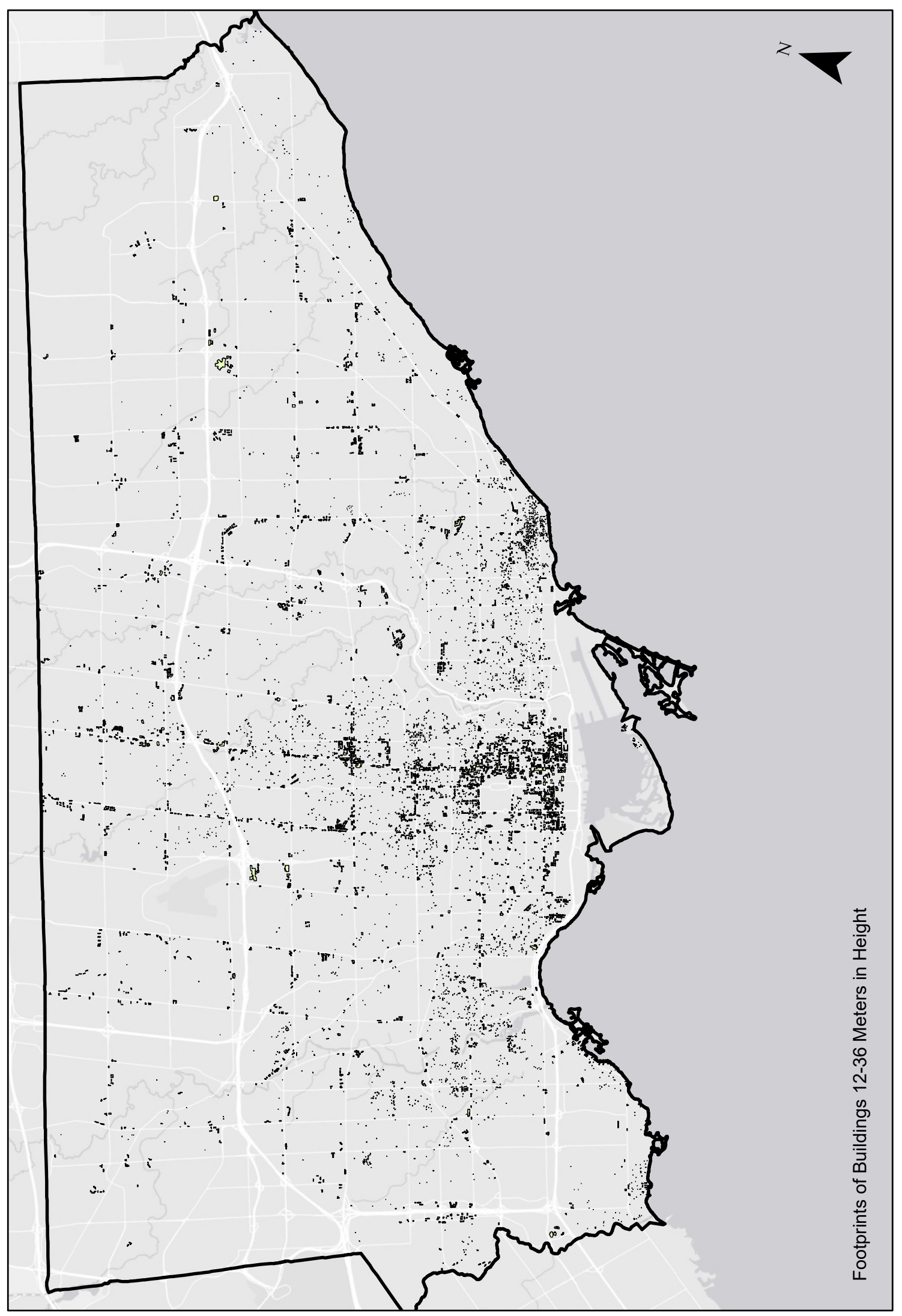




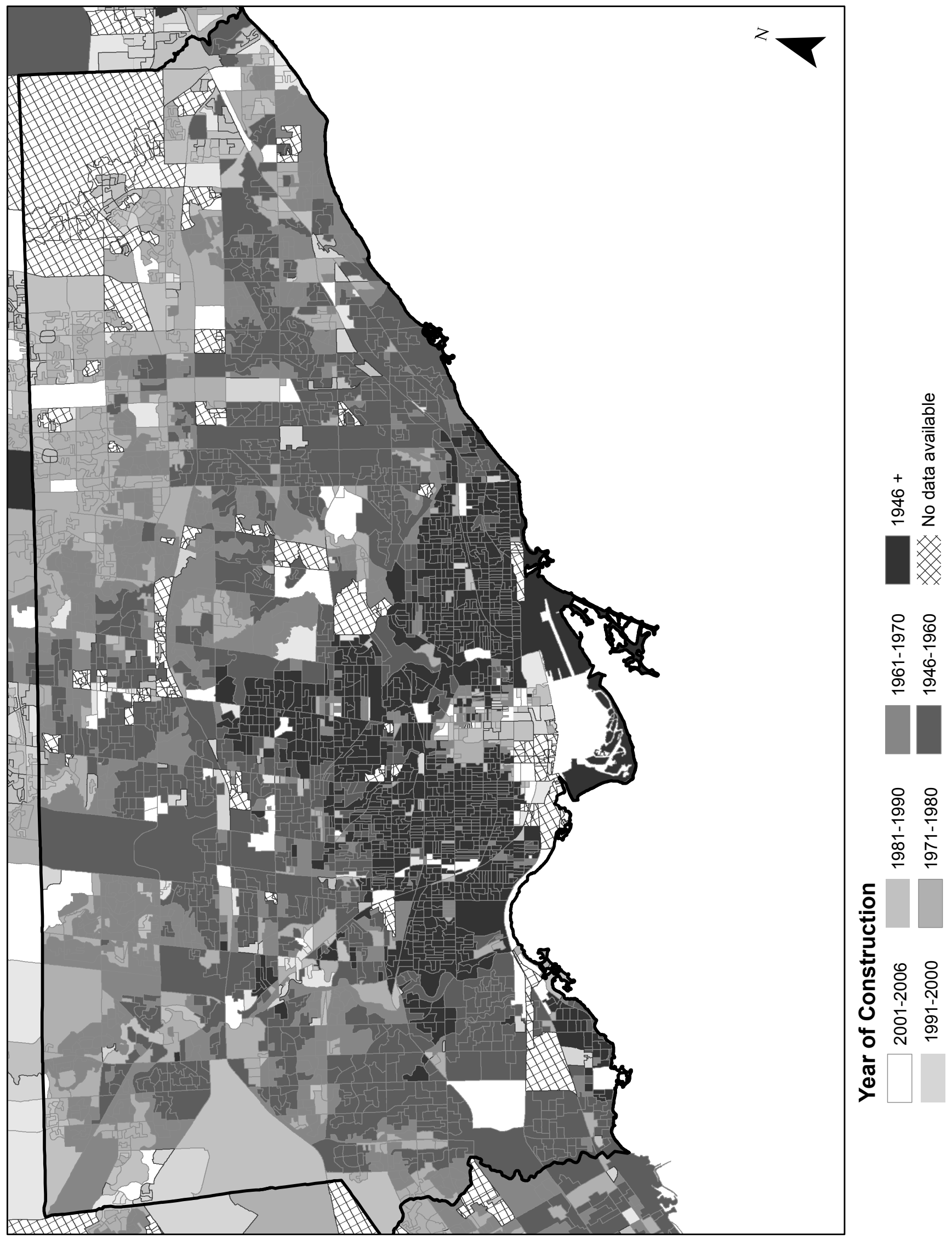



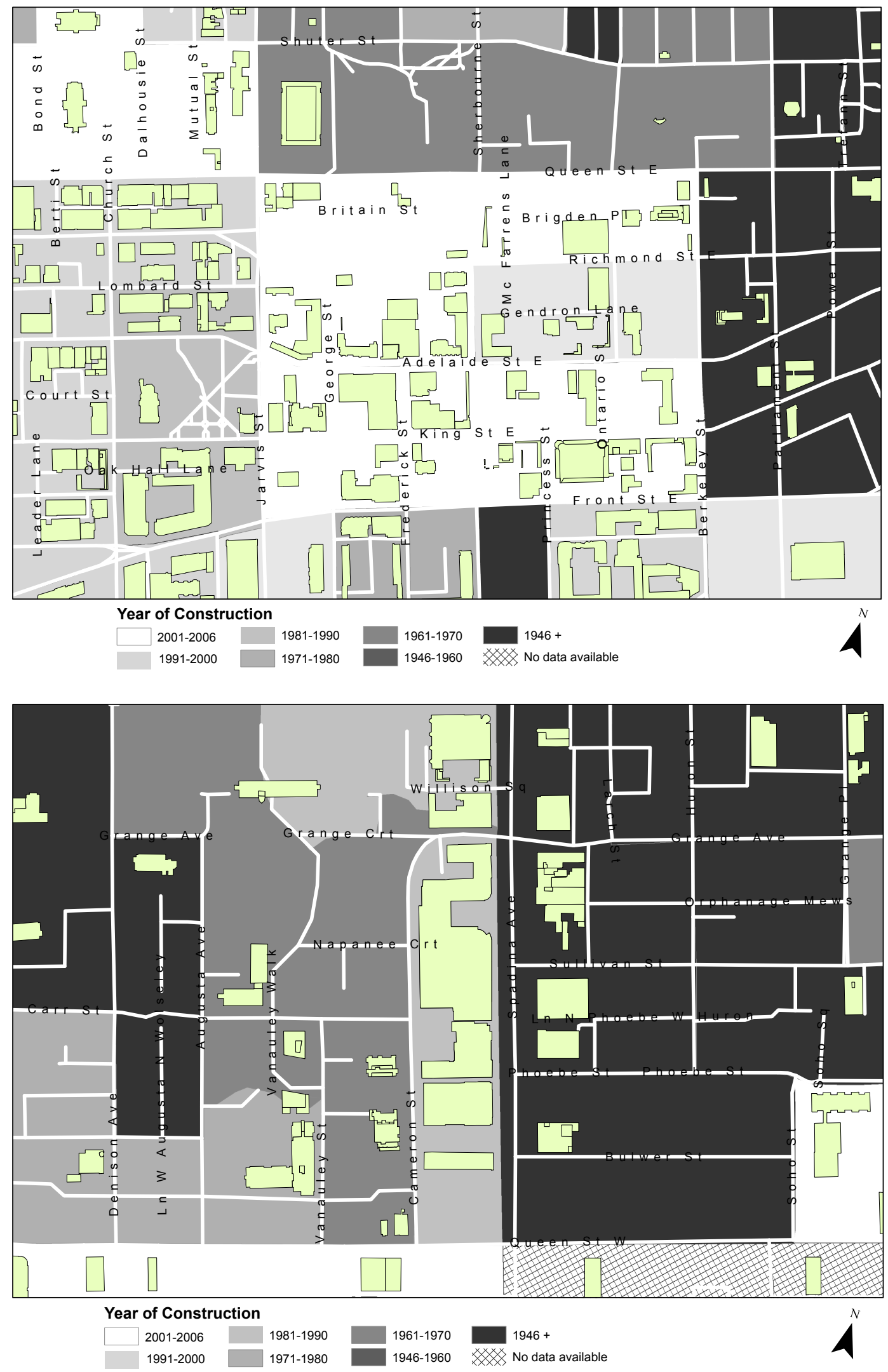

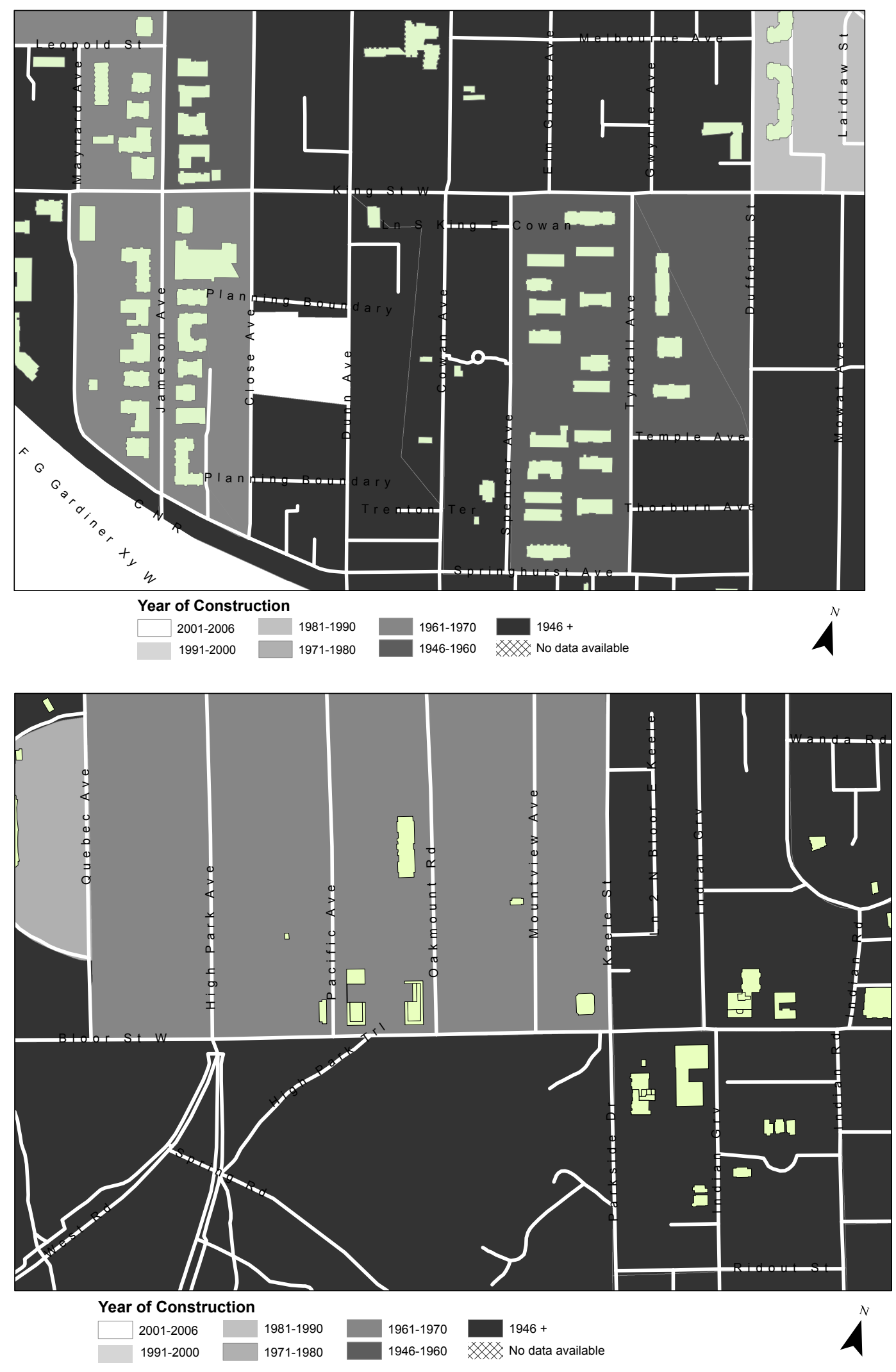

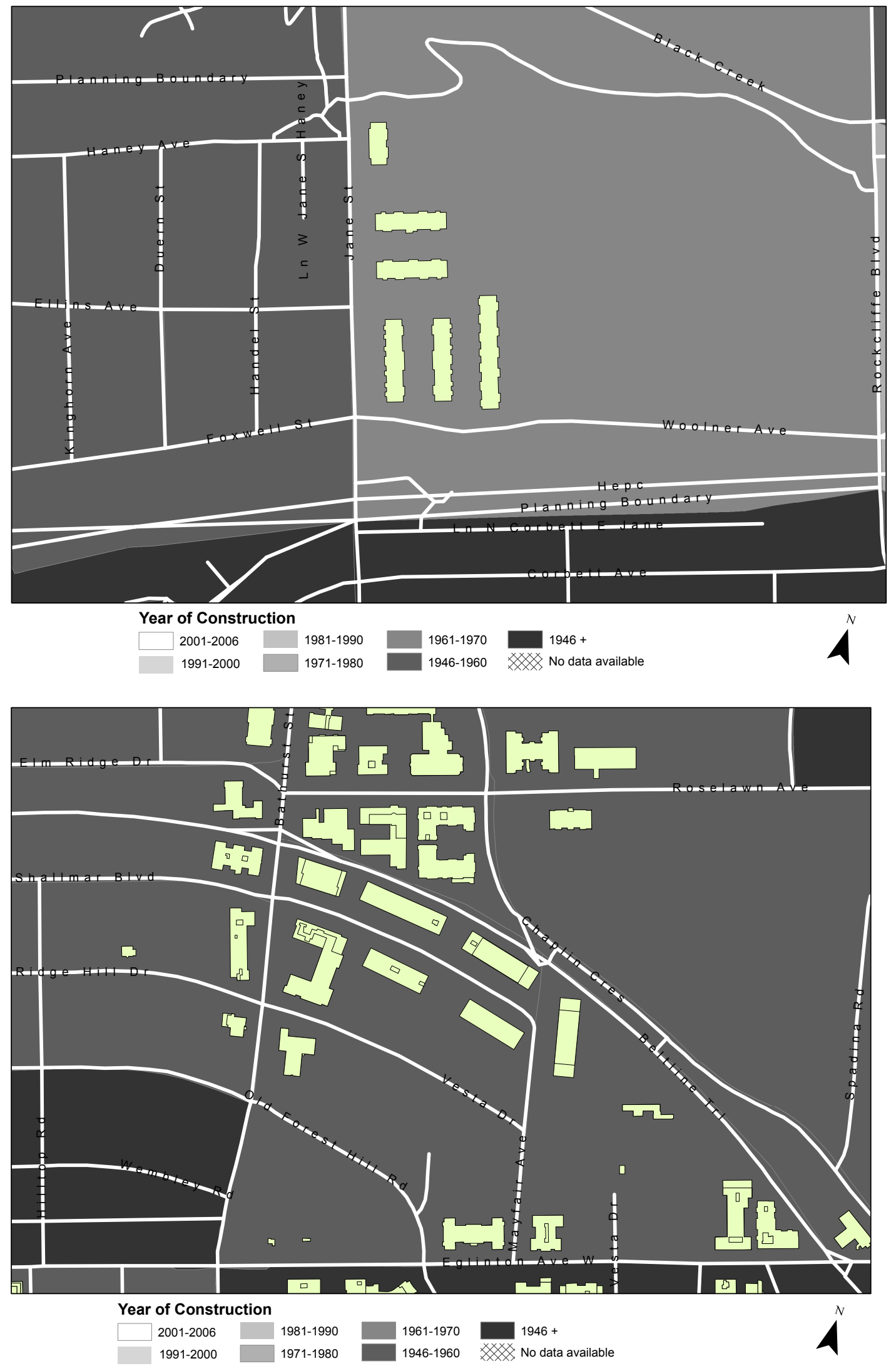

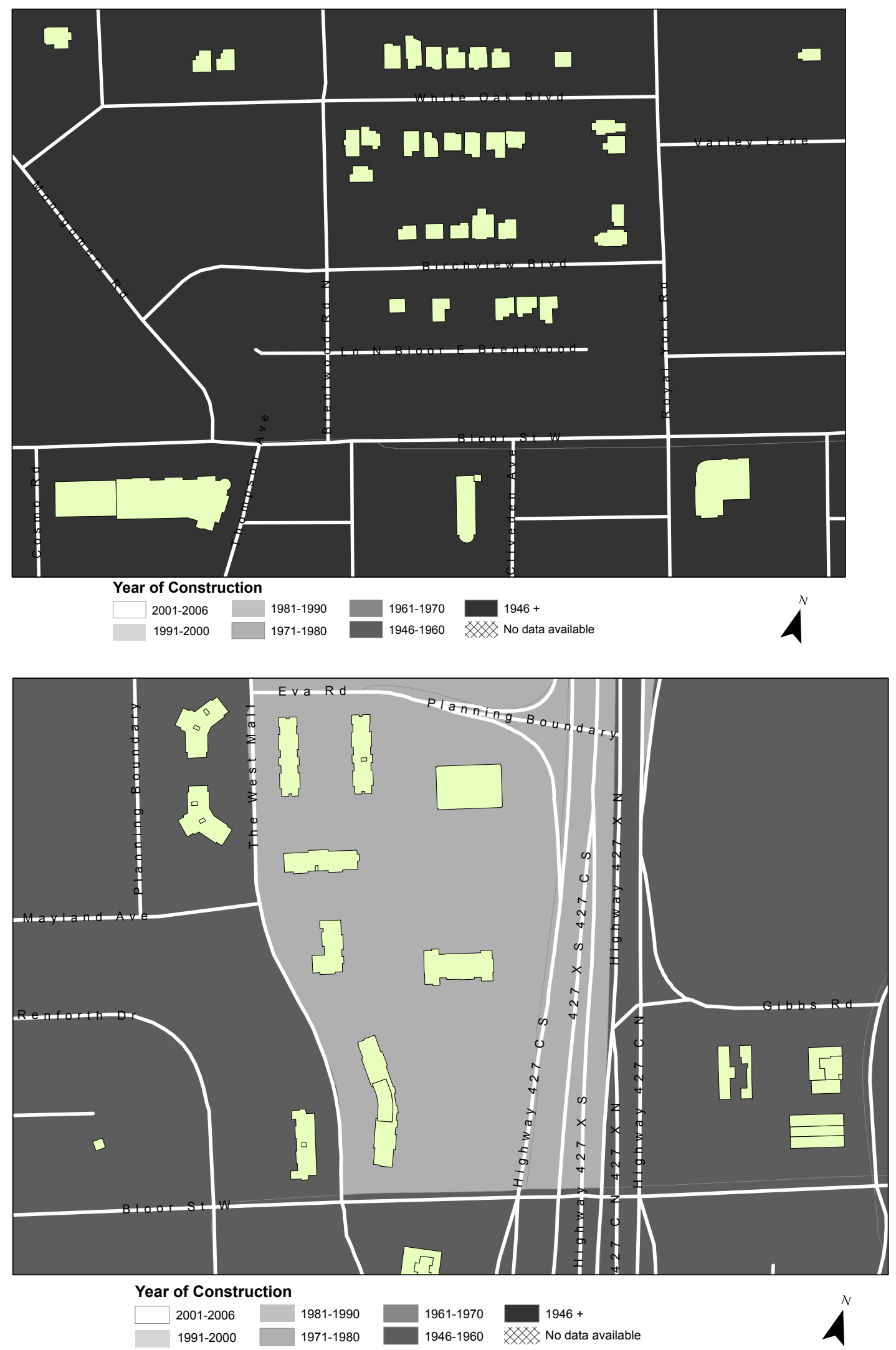